\title{
Modeling the Failure Pattern of Prenotched Recycled Aggregate Concrete Using FEM on Complementary Energy Principle
}

\author{
Yao Wang $\left(\mathbb{D},{ }^{1,2}\right.$ Gang Zong $\left(\mathbb{D},{ }^{1}\right.$ Juan Liu $\mathbb{D},{ }^{1}$ Chunyang Wu $\mathbb{D},{ }^{1}$ Minyao Xu $\mathbb{D},{ }^{1}$ \\ and Jing Zhao $\mathbb{1}^{1}$ \\ ${ }^{1}$ Department of Architecture and Engineering, Yancheng Polytechnic College, Yancheng, Jiangsu 224005, China \\ ${ }^{2}$ Department of Architecture and Engineering, Beijing University of Technology, Beijing 100124, China \\ Correspondence should be addressed to Minyao Xu; minyaoxu@yctei.edu.cn
}

Received 26 October 2020; Revised 8 January 2021; Accepted 27 January 2021; Published 8 February 2021

Academic Editor: Bekir Sahin

Copyright (c) 2021 Yao Wang et al. This is an open access article distributed under the Creative Commons Attribution License, which permits unrestricted use, distribution, and reproduction in any medium, provided the original work is properly cited.

\begin{abstract}
The reuse of recycled aggregate concrete (RAC) is being researched all over the world and lots of works are focused on the notched specimen to study the crack path of RAC. A mathematical algorithm of RAC meshing was presented to explore the failure pattern in RAC. According to this algorithm, the interfacial transition zone can be defined to be an actual thickness at the micron level. Further, a new finite element method (FEM) on the complementary energy principle was introduced to simulate the mechanical behavior of RAC's mesostructure. The compliance matrix of the element with any shape can be calculated and expressed to be a uniform and explicit expression. Several numerical models of RAC were established, in which the effecting factors of the prenotch size, thickness of ITZ, and the distance from the prenotch to the aggregate were taken into account. Hereafter, these RAC models were subjected to uniaxial tension. The effect of the aforementioned factors on the crack path was simulated. The simulated data manifest that both the mesh mode of RAC and the FEM on complementary energy principle are effective approaches to explore the failure pattern of RAC. The size of the prenotch, thickness of ITZ, and distance from the prenotch to the recycled aggregate have a powerful influence on the path and distribution of the isolated crack, width and length of the crack path, and the shape and path of continuous cracks, respectively.
\end{abstract}

\section{Introduction}

Ordinary concrete has been accepted to be one of the most exceedingly needed construction building materials [1]. Meanwhile, as one of the most commonly used materials in civil engineering, a great deal of research has been carried out to study its static properties $[2,3]$ and dynamic properties [4-6]. At the macro level, the main ingredients of this material are cement, coarse aggregate, and water. The coarse aggregate can be obtained from natural resources, which are finite and limited. From the perspective of saving and reusing natural resources, the waste concrete can be completely reused in civil engineering, namely, recycled aggregate $[7,8]$. As a recyclable material, the recycled aggregate can be obtained by crushing the waste concrete. Due to the treatment method, the component of recycled aggregate differs from the natural aggregate [9-11]. In the process of treatment, an uncertain percentage of old mortar will inevitably be coherent around the recycled aggregate. Unfortunately, this adhered mortar is the main reason that both the macrostructure and the mechanical properties of recycled aggregate are inferior to those of ordinary aggregate. However, compared with ordinary concrete, although recycled aggregate concrete (RAC) has defects in strength and workability, it can still be employed in engineering $[7,12]$.

Fruitful works of RAC failure mode have been obtained by means of experimental tests and numerical simulations on the macroscale $[11,13,14]$, mesoscale $[15,16]$, microcosmic [17-19], and nanoscale [20-22]. At mesoscale, the RAC is considered as a five-phase system, i.e., recycled aggregate, adhered mortar attached on the surfaces of recycled aggregate, cement mortar, old interfacial transition zone (ITZ), and new ITZ. Since the thickness of ITZ has been observed and measured to be $45 \mu \mathrm{m}-65 \mu \mathrm{m}$ [23] and some cracks up to $13 \mu \mathrm{m}$ at its contact surface with the 
aggregate [24], it is difficult to investigate its effect on the cracking process and fracture mode owing to such a thin thickness and complicated structure. Consequently, there are three cases of the continuous numerical models via numerical simulation method; namely, one is the model that considered the existence of the ITZs [25-27], the other is the model where the ITZs are not taken into account $[28,29]$, and the third one is to insert into a zero-thickness element to represent the ITZ, e.g., cohesive zone elements [30-32], Goodman-type elements [33], or rigid body spring model [34-36]. As for the first case, the thicknesses of ITZ were varying from $0.2 \mathrm{~mm}$ to $2.0 \mathrm{~mm}$, and only a little work focused on the actual thickness of ITZ $[15,26]$. Even when dealing with complex 3D fractures in reinforced concrete structures, the influence of the ITZ on the cracking mode has to be considered $[37,38]$. Therefore, numerous studies have shown that ITZ has an important role in influencing the performance of concrete and its structures.

From the perspective of material damage mode, cracking is a wide-spreading failure in RAC. Therefore, a lot of numerical models of RAC have been presented and simulated to explore the crack mode of RAC. Xiao et al. [23] and Li et al. [39] adopted a model of nine recycled aggregates to explore the crack process of RAC under uniaxial tension using the software of ABAQUS; the results showed that there has been a significant strain concentration around the ITZs and cracks appeared first and then the cracks propagated to the adhered mortar and cement mortar, forming a continuous crack. Wang et al. [15] explored the effects of ITZ thickness and mechanical properties on the crack pattern; the simulated results demonstrated that the old ITZ has a meaningful effect on the failure pattern compared to the effect of the new ITZ. Guo et al. [40] performed a RAC model that takes into account effective interphase and the randomness of adhered mortar to study their effects on the crack path of RAC; the damage localization displayed that the crack path extended not only to adhered mortar and effective interphase but also in recycled aggregate. Previous numerical studies have engaged in the effects of mechanical properties and characteristics of a five-phase system on the stress-strain curves, damage pattern, or stress/strain concentration. Further, the actual thickness of ITZ at the micron level was not taken into consideration in the numerical model.

With the development of computer computational efficiency, numerous efficient numerical simulation methods have been proposed and widely used to explore the mechanical properties of materials and structures [41]. A number of two-dimensional [25, 26, 42-45] and three-dimensional $[30,46]$ models of concrete materials or structures have been developed to study their mechanical properties. In addition, numerous efficient numerical simulation methods have been developed, for instance, FEM, meshfree method [47, 48], discrete element method $[49,50]$, finite difference method [51], extended FEM [32, 37, 52-54], rigid body spring method [34-36], hybrid stress method [55, 56], the Alpha FEM [57], and the unsymmetric method [58]. From the point of view of the energy principle, the FEM method can be divided into two types, i.e., methods based on the potential energy principle and methods based on the complementary energy principle. However, when studying the failure mode of materials at mesoscale, most numerical simulation software and methods use the potential energy principle, whereas few software and methods use the complementary energy principle.

As for the complementary energy principle, the stress interpolation function of the element needs to be constructed first. However, the interpolation function must be guaranteed to be balanced within the element, at the element boundary, and at the stress boundary, which is very difficult. In addition, it must be solved by Gaussian integration to obtain the compliance matrix. Moreover, it is also difficult to solve the nodal displacement after obtaining the stress. The complementary energy principle, which is the counterpart of the potential energy principle, has rarely been applied to study the mesoscale damage analysis of materials. Therefore, further efforts should be carried out using the FEM based on the complementary energy principle to evaluate the damage mechanism of RAC.

Herein, first, a mesh method was proposed, in which the actual thickness of ITZ can be built at the micron level. A RAC numerical model that can simulate the actual thickness of ITZ was established using this mesh method. In addition, a new FEM method, named base force element method on complementary energy principle, was employed.

As for the constitutive model of concrete, a number of effective concrete constitutive models have been proposed to study the evolution of internal crack patterns, for instance, multiphysics constitutive models [32, 59], elastic-plastic model [60], nonuniform hardening plasticity model [61], plastic model [62], plastic-fracture model [63], viscoelastic/ plastic model [64], intrinsic time theoretical model [65], plastic-damage model [66], Ottosen constitutive model [67], and Guo-Xu model [68]. In addition, these models have been proven to be effective in stimulating the damage mechanisms of concrete materials and have been widely used and promoted. In this article, a polyline damage constitutive relationship [69] was applied to represent the mechanical and deformation properties of RAC's five-phase medium. With this model, the full stress-strain curve of recycled concrete under load can be well captured. The model is not described in detail in this article to avoid duplication of work, and details can be found in [69]. For the RAC model, several uniaxial tension tests were simulated; herein, the load was restrained by displacement, which was $0.0005 \mathrm{~mm} /$ step.

The results from our previous studies have shown that the thickness of the ITZ has a significant effect on the development and extension of cracks [15]. However, as mentioned earlier, most of the scholars have established the numerical models of concrete composites with ITZ thicknesses between $0.2 \mathrm{~mm}$ to $2.0 \mathrm{~mm}$, and few models could reflect the actual thickness of ITZ. This thickness differs significantly from the actual thickness, which may affect the accuracy of the results. In addition, almost all of the FEMs for damage problems of concrete composites were based on the potential energy principle, and few FEMs have been presented from the viewpoint of the complementary energy principle. As two branches of the energy principle, the 
complementary energy principle can be as effective as the potential energy principle for material damage. These two energy principles are as effective as the displacement method and the force method of structural mechanics. In this article, the above two aspects were considered to investigate the effect of ITZ on the crack pattern of RAC.

\section{Research Significance}

The ITZ plays a powerful role in the initial position and extension path of the crack in RAC. In this article, the thickness of the ITZs phase was simulated with an actual thickness, namely, $0.06 \mathrm{~mm}$ between the actual thickness of $0.045 \mathrm{~mm}$ and $0.065 \mathrm{~mm}$. In addition, the element number of the RAC model was constant and not affected by the thickness of ITZ, which means the unfavorable effect of element number on computational efficiency can be neglected. For FEM, the base force element method on the complementary energy principle is a novel approach to examine the failure pattern of RAC, which can still maintain the accuracy of the numerical result for the elements that have a high aspect ratio. As for the numerical model of RAC, five factors that can affect the crack path were taken into consideration in the RAC model, including the length and height of the prenotch, the thickness of ITZ, and the horizontal and vertical distance from the prenotch to the aggregate.

\section{Simulation Model and Method}

3.1. Mesh Method of RAC. Herein, the FEM model of RAC was simulated to be of a circular shape and meshed with an actual thickness of ITZ, using the software program MATLAB. The meshing process can be divided into three steps: one is the meshing of the three-phase system in the recycled aggregate, the other is the meshing of new cement mortar outside the recycled aggregate, and finally the elements of recycled aggregate and cement mortar are connected, as manifested in Figure 1. It is worth noting that the red element and blue element are corresponding to the old ITZ and new ITZ, respectively.

As for the actual thickness of ITZ, the mesh method was as follows:

(1) Firstly, determine the location of the two types of ITZs; i.e., the old and new ITZ are located inside and outside the adhered mortar. Then, draw two circles at these two positions, marked as Circle-in-1 and Circle-out-1.

(2) Calculate the corresponding points according to the mesh size of the background (cement mortar) and divide Circle-in-1 and Circle-out-1 into corresponding segments' the number of the segments can be calculated as follows:

$$
n=\frac{8(r+1)}{a}+1,
$$

where $r$ is the radius of the circle and $a$ is the mesh size of the background.
(3) Create a circle from Circle-in-1 outward, marked as Circle-in-2, and the distance between the two circles is designed as the thickness of the ITZ, as well as Circle-out-1.

(4) Identify the five-phase system according to the projection mesh method [16]; then the actual thickness of the ITZ model can be established.

Based on this mesh mode, the thickness of ITZ can be meshed to be the actual thickness, namely, $45-65 \mu \mathrm{m}$. Additionally, the total number of elements and the ITZ thickness are independent of each other, which means that the total number of the elements is practically invariable and the computing efficiency will be higher than that of the model presented via the mapping method. To further explain the mesh method of RAC, a model within an aggregate was designed, as displayed in Figure 2. It should be worth noting that the element size of the cement mortar was $0.5 \mathrm{~mm}$ and $1.0 \mathrm{~mm}$, while for the ITZs, the thickness was defined as $0.1 \mathrm{~mm}$ and $0.2 \mathrm{~mm}$.

Even for the concrete modified by additives or the highperformance concretes, the thickness of ITZ is much thinner than that of RAC. It is also possible to establish the mesoscale model of these types of concrete, e.g., with the ITZ thickness of $0.03 \mathrm{~mm}$ and $0.05 \mathrm{~mm}$, as depicted in Figure 3.

3.2. Numerical Model of RAC. Due to the source and the treatment process of recycled aggregate, its surface is inevitably coated with approximately adhered mortar. Therefore, compared with the mesostructure of ordinary concrete, in addition to the aggregate, cement mortar, and new ITZ, the recycled aggregate contains another two phases, i.e., adhered mortar and the old ITZ, that are between adhered mortar and the aggregate. In terms of the FEM model of RAC, the five-phase system was determined based on the average distance $(d)$ between the four nodes of the element and the center of the aggregate. Assume that the thickness of ITZ is $t$, the radius of the aggregate is $r$, and the thickness of adhered mortar is $h$; the determination rules are as follows:

(1) Cement mortar: $d>r+t$.

(2) New ITZ: $r+t>d>r$.

(3) Adhered mortar: $r>d>r-h$.

(4) Old ITZ: $r-h>d>r-h-t$.

(5) Aggregate: $d<r-h-t$.

Thereafter, the RAC model can be established, as shown in Figure 4.

According to this model, the phase of ITZs can be precisely distinguished and meshed. Therefore, the mechanical properties of RAC can be investigated on the basis of the actual thickness of RAC. Moreover, compared with the mesh projection method, this mesh dissection does not increase the element number of the model and thereby will improve the computational efficiency. Consequently, the 


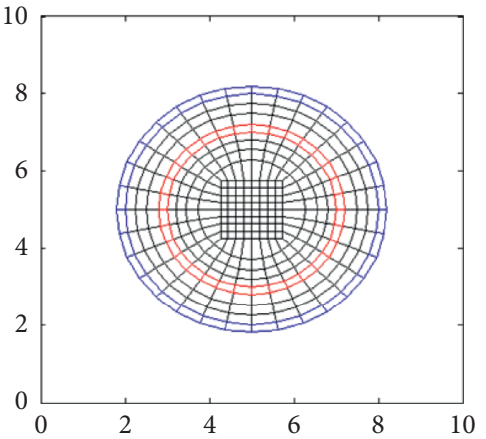

(a)

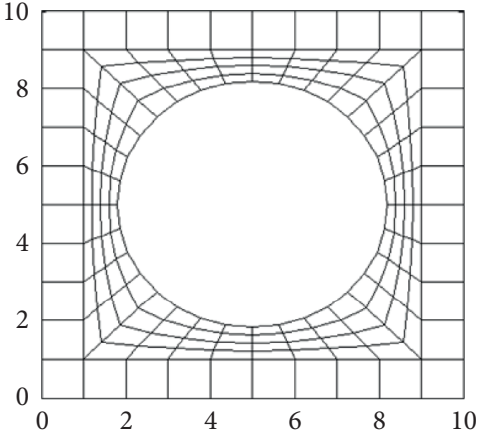

(b)

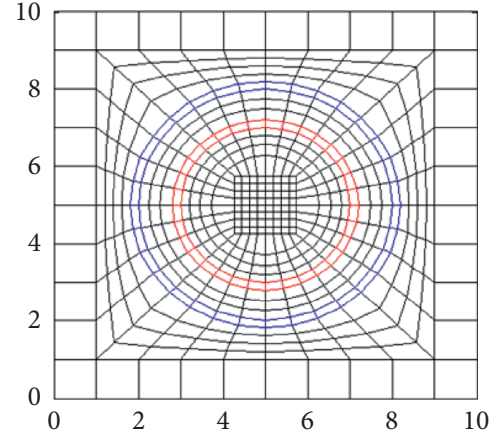

(c)

FIgURE 1: Mesh method: (a) aggregate; (b) cement mortar; (c) mesh model.

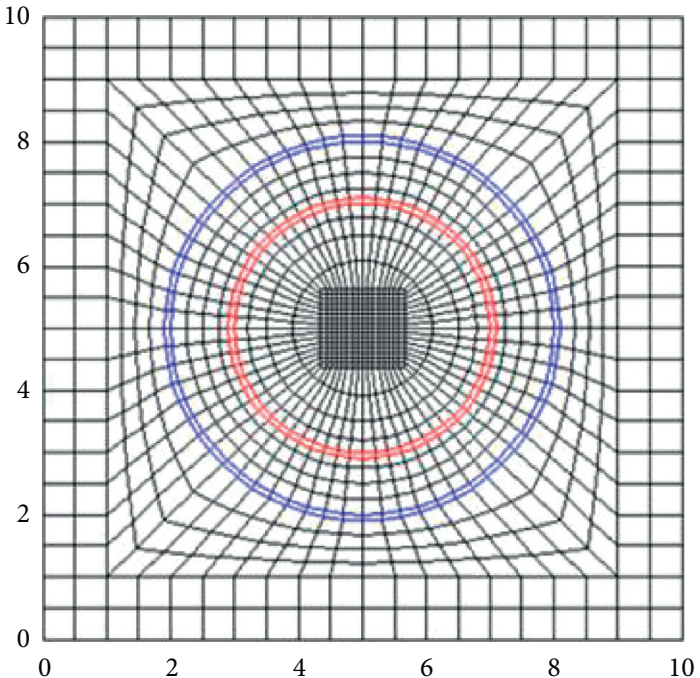

(a)

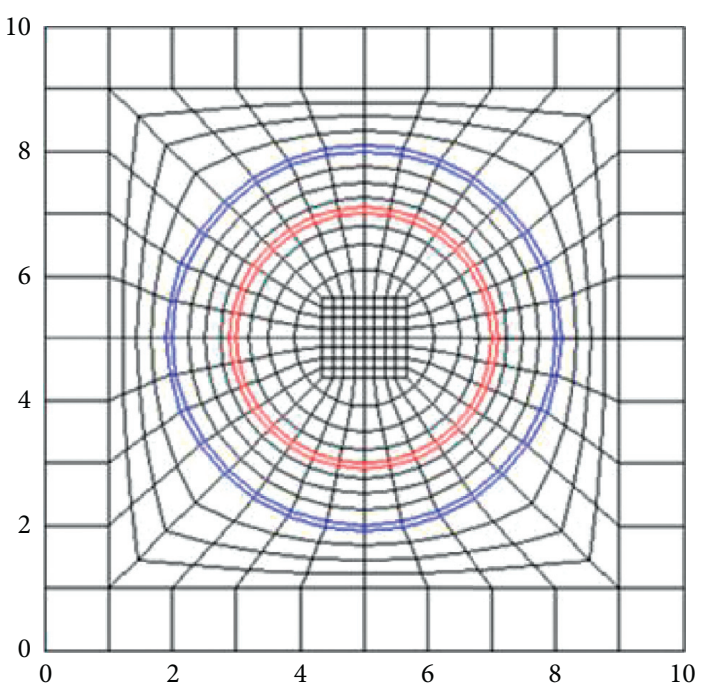

(c)

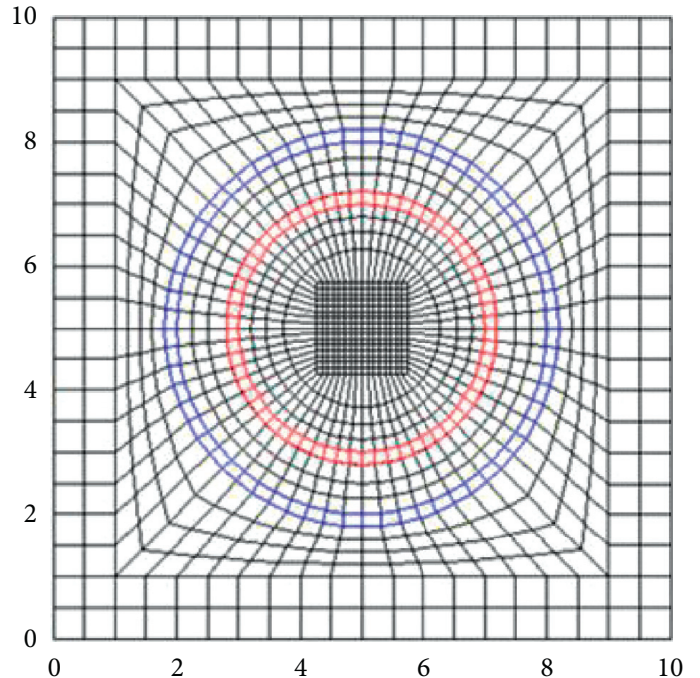

(b)

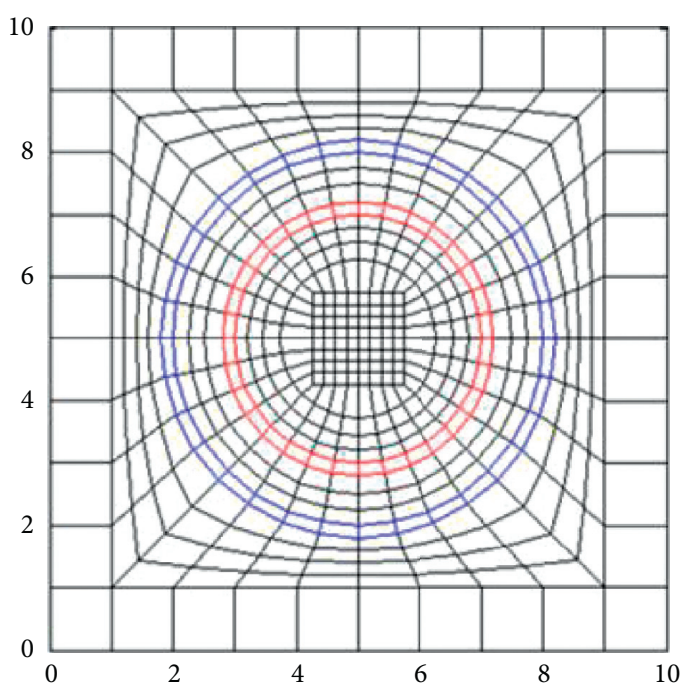

(d)

Figure 2: Mesh mode of RAC: (a) CM=0.5 mm, ITZ =0.1 mm; (b) CM=0.5 mm, ITZ=0.2 $\mathrm{mm}$; (c) $\mathrm{CM}=1.0 \mathrm{~mm}, \mathrm{ITZ}=0.1 \mathrm{~mm}$; (d) $\mathrm{CM}=1.0 \mathrm{~mm}, \mathrm{ITZ}=0.2 \mathrm{~mm}$. Note. Cement mortar is abbreviated as CM. 


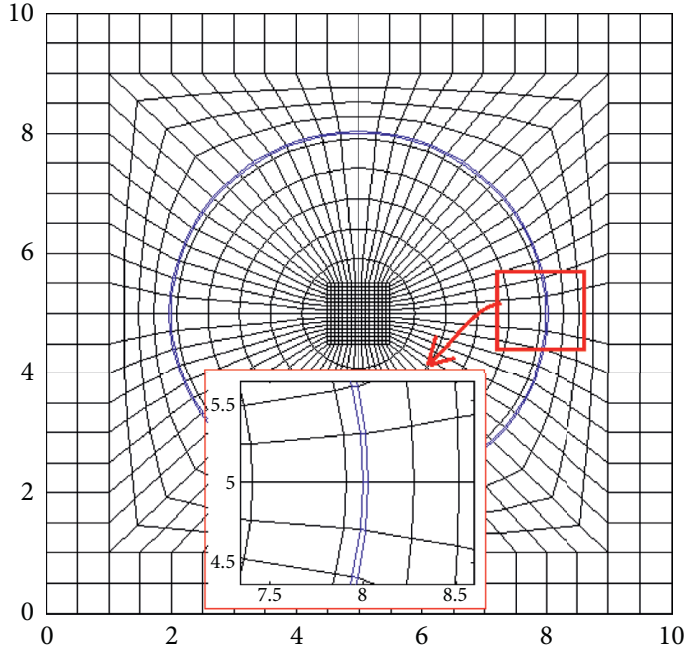

(a)

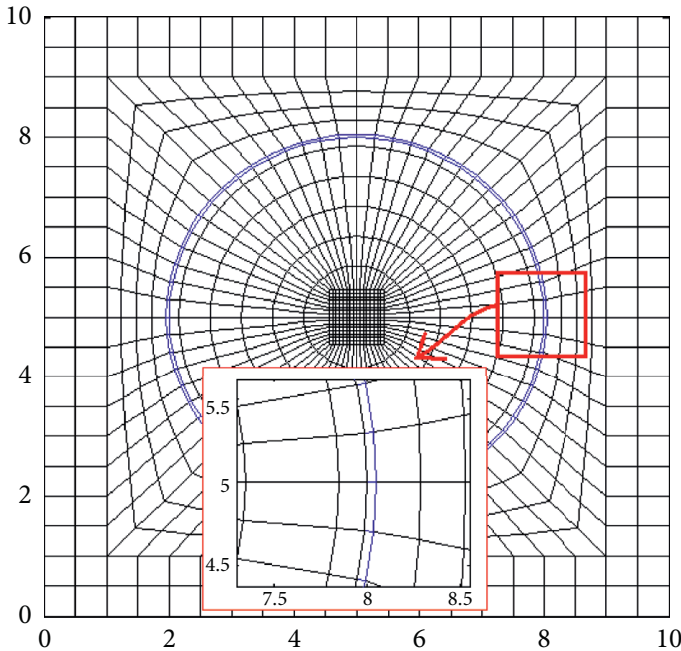

(b)

Figure 3: Models with thinner ITZ: (a) $\mathrm{CM}=0.5 \mathrm{~mm}$, ITZ $=0.03 \mathrm{~mm}$; (b) $\mathrm{CM}=0.5 \mathrm{~mm}$, ITZ $=0.05 \mathrm{~mm}$.

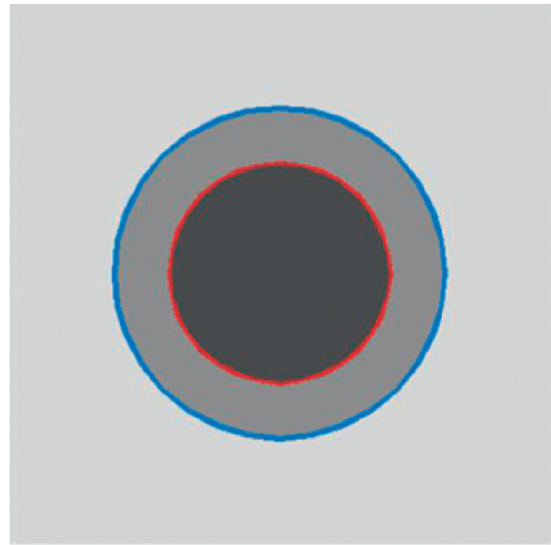

(a)

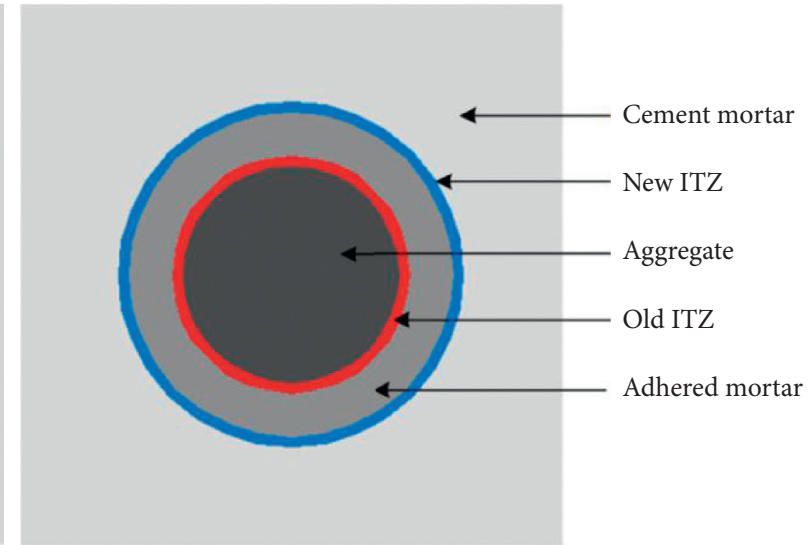

(b)

Figure 4: FEM of RAC: (a) ITZ=0.1 mm; (b) ITZ $=0.2 \mathrm{~mm}$.

mesostructure of RAC can be modeled with an actual thickness of ITZ and fewer element numbers.

Since the concrete containing nine recycled aggregate specimens was employed by Li et al. [70], the numerical model of this specimen has been successfully used to consider the influences of (1) relative mechanical properties between cement mortar and ITZ and (2) thickness of ITZ on the mechanical properties and crack path $[15,23]$. Prior studies demonstrated that this numerical model of RAC is an efficient model to characterize the physical and mechanical properties of RAC. Therefore, in this article, this numerical model was selected and meshed by the current mesh method, as exhibited in Figure 5.
3.3. Base Force Element Method. In this article, the base force element method on the complementary energy principle was selected to examine the failure pattern of RAC. As was previously mentioned, the base force is the theoretical basis of the base force element method [71]. Therefore, in deriving the compliance matrix and nodal displacement of the element, the concept of base force is first briefly introduced. Consider a hexahedron element with one in-plane node per face, as displayed in Figure 6.

A force acts on each face-in-node, marked as $\mathbf{T}$, with the following expression:

$$
\mathbf{T}^{i}=\frac{1}{\mathrm{~d} x^{i+1} \mathrm{~d} x^{i-1}} \mathrm{~d} \mathbf{T}^{i}, \quad \mathrm{~d} x^{i} \longrightarrow 0,
$$




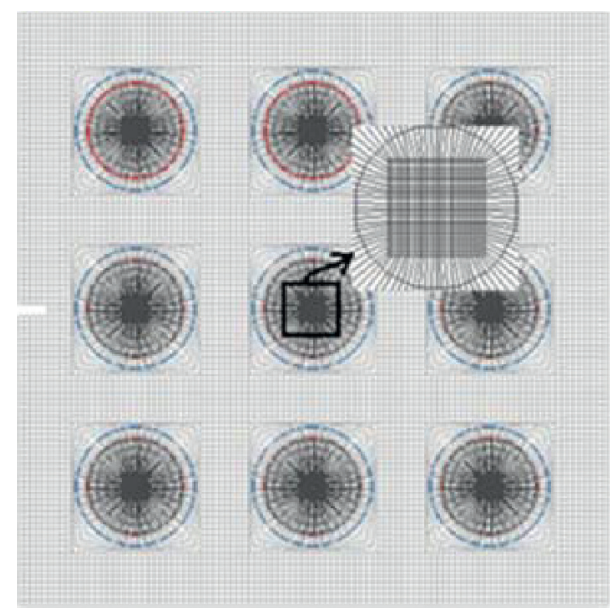

(a)

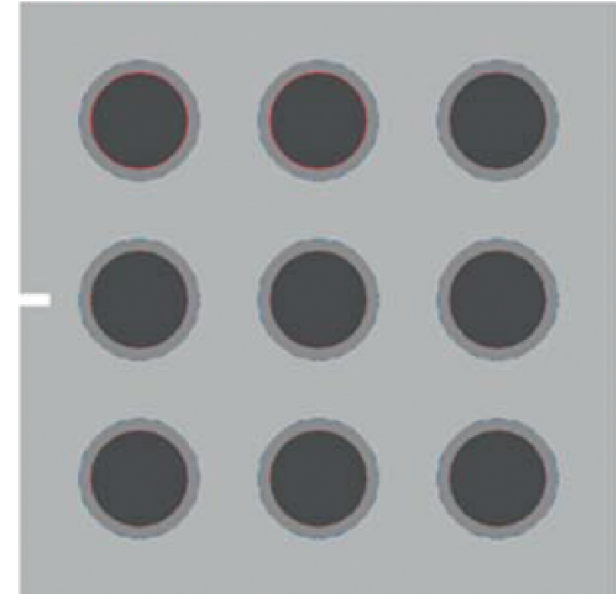

(b)

Figure 5: RAC model: (a) mesh method; (b) FEM model.

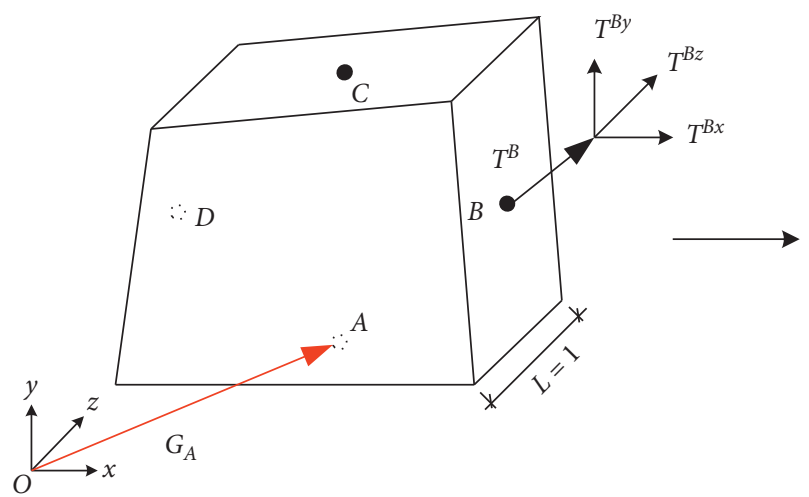

(a)

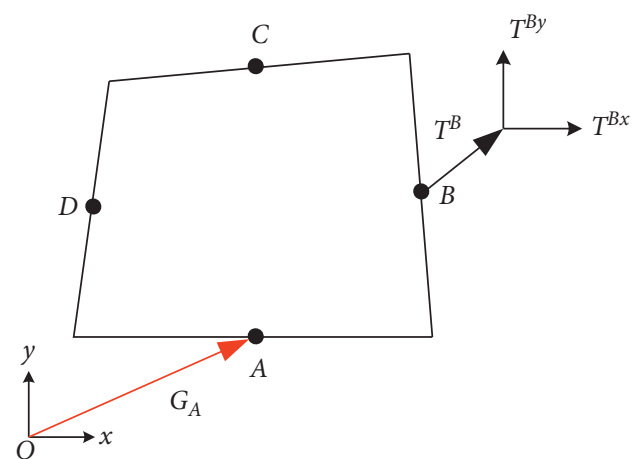

(b)

FIgURE 6: Element of base force element method: (a) three-dimensional element; (b) a planar element.

where $\mathbf{T}^{i}(i=1,2,3)$ is the base force.

As for the static problems, the equilibrium equation can be expressed as follows:

$$
\frac{\partial}{\partial x^{i}} \mathbf{T}^{i}+V \rho \mathbf{f}=0
$$

where $V, \rho, \mathbf{f}$ sequentially express the element volume, density, and force acting on per mass.

The boundary condition can be described as Figure 7. The boundary conditions can be written as follows:

$$
\begin{array}{rlr}
u & =\bar{u}, \quad \text { On } S_{u} ; \\
\frac{1}{V} \mathbf{T}^{i} \mathbf{n}_{i} & =\overline{\boldsymbol{\sigma}}, & \text { On } S_{\sigma},
\end{array}
$$

where $\bar{u}$ is known displacement, $\mathbf{T}^{i}$ is the current base force acting on the boundary, and $\mathbf{n}_{i}$ is the outer normal vector.

As for the three-dimensional element, the six nodes on the surface of the element are marked $\alpha(\alpha=A, B, C, \ldots)$, respectively. Let $\mathbf{T}$ express the base force acting on the point in the face; therefore, the Cauchy stress can be expressed by base force as follows:

$$
\boldsymbol{\sigma}=\frac{1}{V} \mathbf{T}^{\alpha} \otimes \mathbf{G}_{\alpha}, \quad(\alpha=A, B, C \ldots),
$$

where $\mathbf{G}$ is the point position vector.

In addition, the first Piola-Kirchhoff stress can be expressed as follows:

$$
\boldsymbol{\tau}=\frac{1}{V_{P}} \mathbf{T}^{\alpha} \otimes \mathbf{P}_{\alpha}
$$




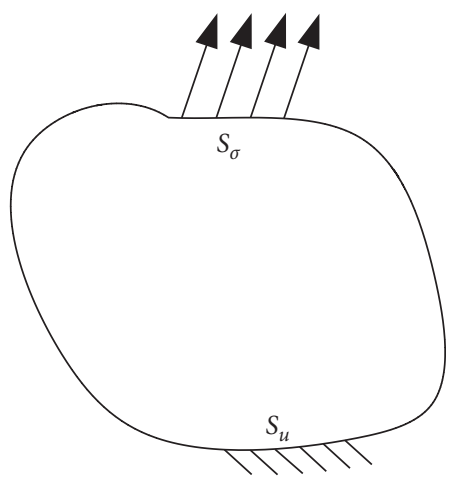

FIgURE 7: Boundary condition.

According to base force, $\mathbf{T}$ and $\mathbf{G}$ can be written as follows:

$$
\begin{aligned}
& \mathbf{T}^{\alpha}=T^{\alpha x} \mathbf{e}_{x}+T^{\alpha y} \mathbf{e}_{y}+T^{\alpha z} \mathbf{e}_{z}, \\
& \mathbf{G}_{\alpha}=G_{\alpha x} \mathbf{e}_{x}+G_{\alpha y} \mathbf{e}_{y}+G_{\alpha z} \mathbf{e}_{z}, \\
& \mathbf{P}_{\alpha}=P_{\alpha x} \mathbf{e}_{x}+P_{\alpha y} \mathbf{e}_{y}+P_{\alpha z} \mathbf{e}_{z} .
\end{aligned}
$$

Then, according to the base force element method, the compliance energy of the three-dimensional element can be expressed as follows:

$$
W_{C}^{e}=\frac{1+v}{2 E V}\left[\left(\mathbf{T}^{\alpha} \cdot \mathbf{T}^{\beta}\right) G_{\alpha \beta}-\frac{v}{1+v}\left(\mathbf{T}^{\beta} \cdot \mathbf{G}_{\alpha}\right)^{2}\right], \quad(\alpha, \beta=A, B, C \ldots) .
$$

Let $E, v, V$ sequentially express the elastic modulus, Poisson's ratio, and element volume. Subsequently, the compliance matrix of the node can be obtained as follows:

$$
\mathbf{C}_{\alpha \beta}=\frac{1+v}{E V}\left(G_{\alpha \beta} \mathbf{U}-\frac{v}{1+v} \mathbf{G} \otimes \alpha \mathbf{G}_{\beta}\right) .
$$

Transforming the tensor form (9) into the form of a matrix, the compliance matrix can be written as follows:

$$
\mathbf{C}_{\alpha \beta}=\frac{1+v}{E V}\left\{\begin{array}{ccc}
\frac{1}{1+v} G_{\alpha x} G_{\beta x}+G_{\alpha y} G_{\beta y}+G_{\alpha z} G_{\beta z} & -\frac{v}{1+v} G_{\alpha x} G_{\beta y} & -\frac{v}{1+v} G_{\alpha x} G_{\beta z} \\
-\frac{v}{1+v} G_{\alpha y} G_{\beta x} & G_{\alpha x} G_{\beta x}+\frac{1}{1+v} G_{\alpha y} G_{\beta y}+G_{\alpha z} G_{\beta z} & -\frac{v}{1+v} G_{\alpha y} G_{\beta z} \\
-\frac{v}{1+v} G_{\alpha z} G_{\beta x} & -\frac{v}{1+v} G_{\alpha z} G_{\beta y} & G_{\alpha x} G_{\beta x}+G_{\alpha y} G_{\beta y}+\frac{v}{1+v} G_{\alpha z} G_{\beta z}
\end{array}\right\} .
$$

The complementary energy function can be obtained by releasing the equilibrium conditions according to the Lagrange multiplier method:

$$
\Pi_{C}^{e *}(\mathbf{T}, \boldsymbol{\lambda}, \boldsymbol{\mu})=\Pi_{C}^{e}(\mathbf{T})+\lambda\left(\sum_{\alpha} \mathbf{T}^{\alpha}\right)+\boldsymbol{\mu}\left(\mathbf{T}^{\alpha} \times \mathbf{G}_{\alpha}\right),
$$

where $\boldsymbol{\lambda}=\left[\lambda_{1}, \lambda_{2}, \lambda_{3}\right], \boldsymbol{\mu}=\left[\mu_{1}, \mu_{2}, \mu_{3}\right]$ are Lagrange multipliers.

Using the Lagrange multiplier method, the governing equations can be obtained:

$$
\begin{aligned}
& \frac{\partial \Pi_{C}^{e *}(\mathbf{T}, \boldsymbol{\lambda}, \boldsymbol{\mu})}{\partial \mathbf{T}}=0 \\
& \frac{\partial \Pi_{C}^{e *}(\mathbf{T}, \boldsymbol{\lambda}, \boldsymbol{\mu})}{\partial \boldsymbol{\lambda}}=0 ; \\
& \frac{\partial \Pi_{C}^{e *}(\mathbf{T}, \boldsymbol{\lambda}, \boldsymbol{\mu})}{\partial \lambda_{3}}=0 .
\end{aligned}
$$

Therefore, the nodal displacement can be obtained as follows: 


$$
\begin{aligned}
\boldsymbol{\delta}_{i} & =\frac{\partial\left(W_{C}^{e}-\bar{u}_{i} \cdot \mathbf{T}^{i}\right)}{\partial \mathbf{T}^{i}}+\lambda \frac{\partial\left(\sum_{i} \mathbf{T}^{i}\right)}{\partial \mathbf{T}^{i}}+\mu \frac{\partial\left(\mathbf{T}^{i} \times \mathbf{r}_{i}\right)}{\partial \mathbf{T}^{i}}, \\
& =\mathbf{C}_{i j} \cdot \mathbf{T}^{j}-\bar{u}_{i}+\boldsymbol{\lambda}+\boldsymbol{\mu} \frac{\partial\left(\mathbf{T}^{i} \times \mathbf{r}_{i}\right)}{\partial \mathbf{T}^{i}} .
\end{aligned}
$$

Transforming the tensor form of nodal displacement into a simplified expression yields the following expression:

$$
\boldsymbol{\delta}=\left\{\begin{array}{l}
\delta_{x}=C_{i x j x} T^{j x}+C_{i x j y} T^{j y}+C_{i x j z} T^{j z}-\bar{u}_{x}+\lambda_{1}+\mu_{2} G_{y}-\mu_{3} G_{z}, \\
\delta_{y}=C_{i y j x} T^{j x}+C_{i y j y} T^{j y}+C_{i y j z} T^{j z}-\bar{u}_{y}+\lambda_{2}-\mu_{1} G_{x}+\mu_{3} G_{z}, \\
\delta_{z}=C_{i z j x} T^{j x}+C_{i z j y} T^{j y}+C_{i z j z} T^{j z}-\bar{u}_{z}+\lambda_{2}+\mu_{1} G_{x}-\mu_{2} G_{y} .
\end{array}\right.
$$

According to the three-dimensional element of the base force element method, a two-dimensional planar element was degenerated by Wang et al., [15], as plotted in Figure 6 . When the three-dimensional element was degenerated into a two-dimensional planar element, only degenerating the volume $V$ to an area $A$ and removing the force and position vector about the $Z$-axis lead to the following expressions of a two-dimensional element.

The Cauchy stress can be written as follows:

$$
\boldsymbol{\sigma}=\frac{1}{A} \mathbf{T}^{\alpha} \otimes \mathbf{G}_{\alpha}, \quad(\alpha=A, B, C \ldots) .
$$

The two concepts of base force and point position vector can be described:

$$
\begin{aligned}
\mathbf{T}^{\alpha} & =T^{\alpha x} \mathbf{e}_{x}+T^{\alpha y} \mathbf{e}_{y}, \\
\mathbf{G}_{\alpha} & =G_{\alpha x} \mathbf{e}_{x}+G_{\alpha y} \mathbf{e}_{y} .
\end{aligned}
$$

Let $A$ express the element area; then the compliance matrix of the planar element can be as follows:

$$
\mathbf{C}_{\alpha \beta}=\frac{1+v}{E A}\left\{\begin{array}{cc}
\frac{1}{1+v} G_{\alpha x} G_{\beta x}+G_{\alpha y} G_{\beta y} & -\frac{v}{1+v} G_{\alpha x} G_{\beta y} \\
-\frac{v}{1+v} G_{\alpha y} G_{\beta x} & G_{\alpha x} G_{\beta x}+\frac{1}{1+v} G_{\alpha y} G_{\beta y}
\end{array}\right\} .
$$

As for the nodal displacement, we can obtain it by releasing the governing equations, as follows:

$$
\boldsymbol{\delta}_{\alpha}=\left\{\begin{array}{l}
\delta_{x}=C_{\alpha x \beta x} T^{\beta x}+C_{\alpha x \beta y} T^{\beta y}+\lambda_{1}-\mu_{2} G_{y}-u_{x}, \\
\delta_{y}=C_{\alpha y \beta x} T^{\beta x}+C_{\alpha y \beta y} T^{\beta y}+\lambda_{2}+\mu_{1} G_{x}-u_{y},
\end{array}\right.
$$

where $\lambda_{1}, \lambda_{2}, \mu_{1}, \mu_{2}$ denote the Lagrange multipliers and $u_{x}, u_{y}$ are the known nodal displacement.
The displacement loading was applied to the top of the model, marked as $\Delta$. Therefore, the element stress can be calculated by the following:

$$
f=\frac{\Delta}{\lambda}
$$

where $\lambda$ is the overall compliance matrix. Thereafter, the Cauchy stress can be obtained by equation (15) and the nodal displacement can be calculated according to equation (19).

For both two-dimensional and three-dimensional elements, it can be observed that the expressions of various vectors are explicit and do not contain Gaussian integrals based on the complementary energy principle and basal force element method. This will increase the accuracy of the calculation results and is one of the advantages compared with the conventional FEMs.

3.4. Accuracy of the Mesh Mode and FEM. In order to confirm the accuracy of the mesh model and FEM on the complementary energy principle, a RAC model was first simulated under uniaxial tension, in which the ITZ size is $0.06 \mathrm{~mm}$. The experimental results indicated that the average mechanical property ratio of ITZs to cement mortar ranged from $50 \%$ to $85 \%$ [23, 72,73$]$. Meanwhile, the study has also shown that the value intervals of these parameters are highly uncertain [45]. In this article, according to our previous work [69], the material parameters of the RAC model are manifested in Table 1. It should be noted that the aggregates in this model were assumed to be ordinary inert aggregates.

The polyline damage model [74] was chosen to describe the stress-strain relationship of the five-phase system, as manifested in Figure 8.

The elastic modulus of the five-phase system can be described as follows:

$$
E=E_{0}(1-d),
$$


TABLE 1: Material parameters of FEM modeling.

\begin{tabular}{|c|c|c|c|c|c|c|}
\hline Phases & Elastic modulus (GPa) & Poisson's ratio & Tensile strength $(\mathrm{MPa})$ & Compressive strength (MPa) & $(\alpha / \beta)$ & $(\lambda / \eta / \xi)$ \\
\hline Aggregate & 70 & 0.16 & 7.0 & 84.0 & $0.40 / 0.50$ & $0.90 / 4 / 10$ \\
\hline Adhered mortar & 25 & 0.22 & 2.6 & 31.2 & $0.55 / 0.60$ & $0.40 / 6 / 10$ \\
\hline Cement mortar & 30 & 0.22 & 3.2 & 38.4 & $0.55 / 0.60$ & $0.30 / 4 / 10$ \\
\hline Old ITZ & 18 & 0.20 & 2.0 & 20.0 & $0.50 / 0.50$ & $0.40 / 6 / 10$ \\
\hline New ITZ & 22 & 0.20 & 2.3 & 23.0 & $0.50 / 0.50$ & $0.40 / 6 / 10$ \\
\hline
\end{tabular}

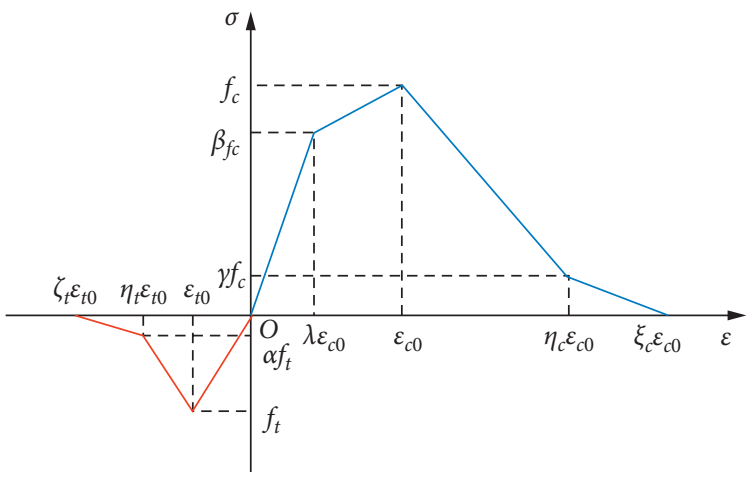

FIgUre 8: Polyline damage model of RAC.

where $E, E_{0}$ represent current and initial values of elastic modulus and $d$ represents the damage factor as follows:

$$
d_{t}=\left\{\begin{array}{lc}
0, & \varepsilon \leq \varepsilon_{t 0}, \\
1-\frac{\varepsilon_{t 0}}{\varepsilon}+\frac{\varepsilon-\varepsilon_{t 0}}{\eta_{t} \varepsilon_{t 0}-\varepsilon_{t 0}} \frac{\varepsilon_{t 0}}{\varepsilon}(1-\alpha), & \varepsilon_{t 0}<\varepsilon \leq \eta_{t} \varepsilon_{t 0}, \\
1-\frac{\alpha}{\xi_{t}-\eta_{t}} \frac{\varepsilon-\eta_{t} \varepsilon_{t 0}}{\varepsilon}+\frac{\alpha \varepsilon_{t 0}}{\varepsilon}, & \eta_{t} \varepsilon_{t 0}<\varepsilon \leq \xi_{t} \varepsilon_{t 0}, \\
1, & \varepsilon \leq \lambda \varepsilon_{c 0}, \\
1-\frac{\beta}{\gamma}, & \begin{array}{ll}
\varepsilon & \xi_{t} \varepsilon_{t 0}, \\
1-\frac{1-\beta}{1-\lambda} \frac{\varepsilon-\lambda \varepsilon_{c o}}{\varepsilon}-\beta \frac{\varepsilon_{c o}}{\varepsilon}, & \lambda \varepsilon_{c 0}<\varepsilon \leq \varepsilon_{c 0}, \\
1-\frac{1-\gamma}{1-\eta_{c}} \frac{\varepsilon-\varepsilon_{c o}}{\varepsilon}-\frac{\varepsilon_{c o}}{\varepsilon}, & \varepsilon_{c 0}<\varepsilon \leq \eta_{c} \varepsilon_{c 0}, \\
1-\frac{\gamma \varepsilon_{c 0}}{\varepsilon}, & \varepsilon>\xi_{c} \varepsilon_{c 0},
\end{array}
\end{array}\right.
$$

where $d_{t}, d_{c}$ are the damage factors for tension and compression; $\varepsilon_{t 0}, \varepsilon_{c 0}$ are the peak strain; $f_{t}, f_{c}$ express the tensile and compressive strength; $\lambda, \eta, \xi$ represent coefficients of elastic strain, residual strain, and ultimate strain; $\alpha, \beta$ are the coefficients of residual tensile/compressive strength. The values of these parameters are listed in Table 1. It should be mentioned that the failure principle is governed by the criterion of maximum tensile strain.

The obtained crack development was compared with that by Xiao et al. [23]. As can be seen, there is clearly good agreement between Figure 9(a) and 9(b). Several isolated cracks formed at the ITZs, which were distributed in the upper and lower areas of the recycled aggregate. Finally, several isolated cracks connected and formed a continuous crack through the specimen.

\section{Results and Discussions}

In this section, several RAC models with nine recycled aggregates were established to study the size effect of the unilateral prenotch on the crack path. Herein, the length size of prenotch was increasing from $0 \mathrm{~mm}$ to $45 \mathrm{~mm}$, with the stepwise increase of $5 \mathrm{~mm}$, and the prenotch height size was constant of $2 \mathrm{~mm}$. Further, the effect of the height of prenotch was also studied by increasing the size from $5 \mathrm{~mm}$ to $50 \mathrm{~mm}$. Additionally, a series of RAC models with one recycled aggregate was also established to study the effects of ITZ size and distance from the prenotch to the edge of the recycled aggregate on the crack path. For these models, the dimension was $100 \mathrm{~mm} \times 100 \mathrm{~mm}$. These models were tested in tensile load, which was restrained by the displacement, $0.0005 \mathrm{~mm} / \mathrm{step}$.

4.1. Size of the Prenotch. To study the influence of prenotch size, 20 numerical models of RAC with a prenotch were performed under uniaxial tension, by varying the length and height of the prenotch, as plotted in Figure 10. The tensile strength and crack paths were simulated as follows. 

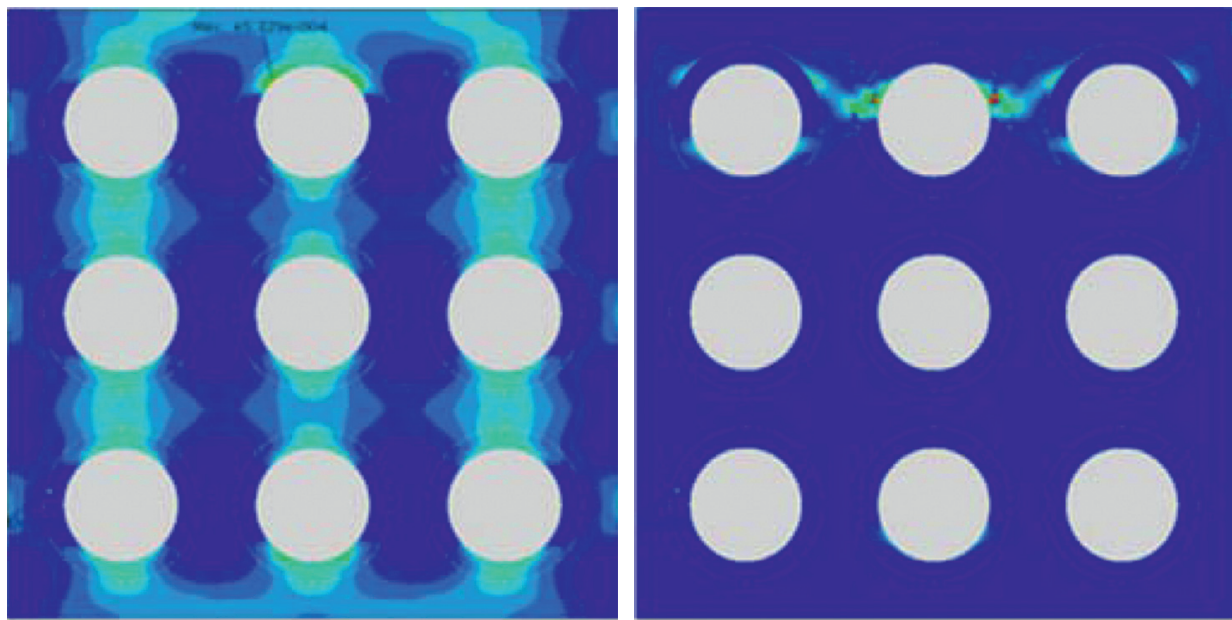

(a)
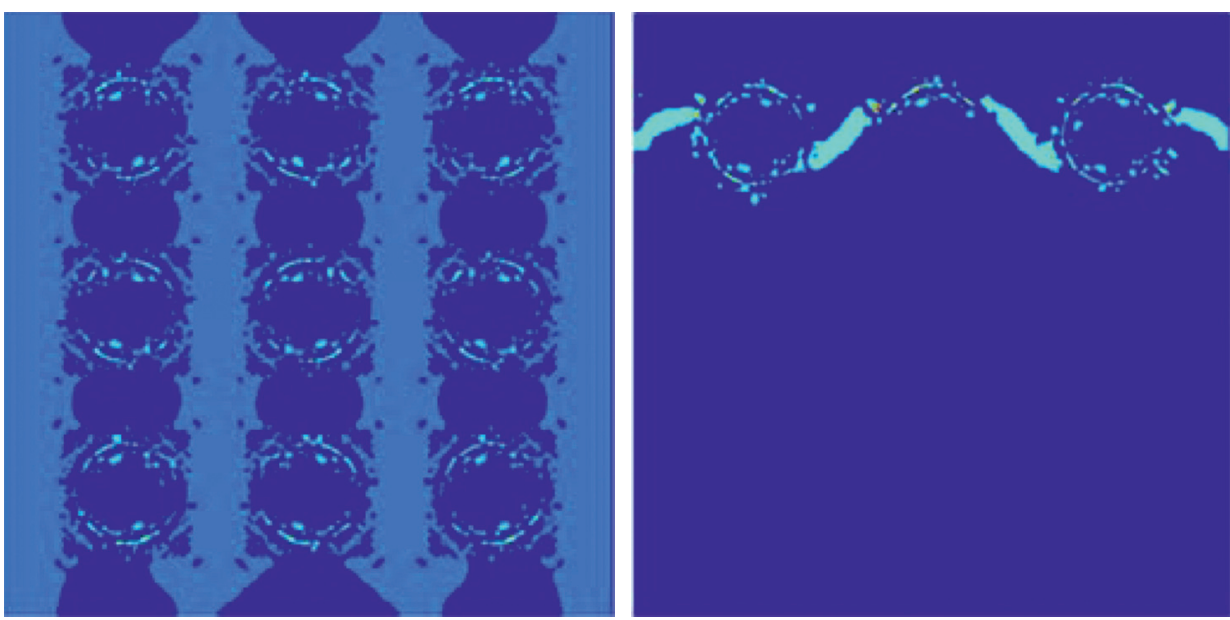

(b)

Figure 9: Comparison of the crack development of RAC: (a) Xiao et al. [23]; (b) present work.

4.1.1. Length of the Prenotch. Ten numerical models of RAC by increasing the length of the prenotch from $0 \mathrm{~mm}$ to $45 \mathrm{~mm}$ with a stepwise increase of $5 \mathrm{~mm}$ were performed, in which the prenotch height was $2 \mathrm{~mm}$.

To illustrate the influence of prenotch length on the crack path, the crack paths of RAC with different prenotch lengths were plotted in Figure 11. Compared with the specimen with a prenotch length of $0 \mathrm{~mm}$, it can be clearly observed that the cracks are evenly distributed around each recycled aggregate, especially in the top zones and bottom zones of recycled aggregate. However, an increasing length of prenotch results in a decrease in the number of cracks. An interesting phenomenon is that the cracks always appeared at the other sides of the prenotch, instead of the side of the prenotch.

The obtained tensile strength by differing the prenotch length is detailed in Figure 12. As can be noticed from Figure 12, as the prenotch length increases, the tensile strength shows a decrease from $3.0 \mathrm{MPa}$ to $1.50 \mathrm{MPa}$, a reduction of $50 \%$. Further, an interesting phenomenon is also observed; that is, the reduction trend seems to be related to the relative bearing surface, as seen in Figure 12. Herein, the relative bearing surface is the ratio between the values of

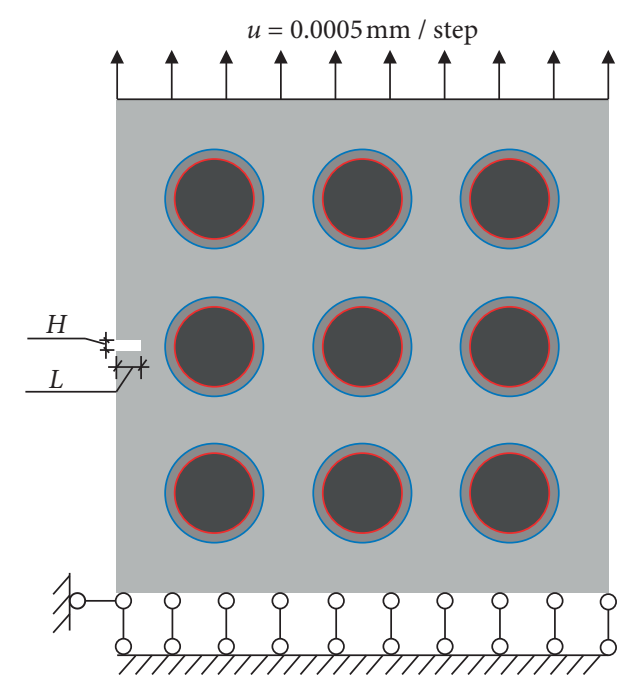

Figure 10: Loading pattern of RAC model.

broad minus the prenotch length to the specimen broad. This fact indicates that the prenotch length plays a significant role in the tensile strength. 


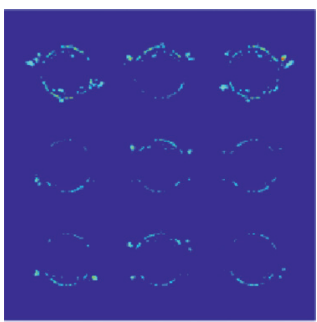

(a)

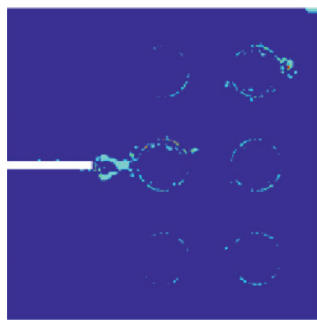

(f)

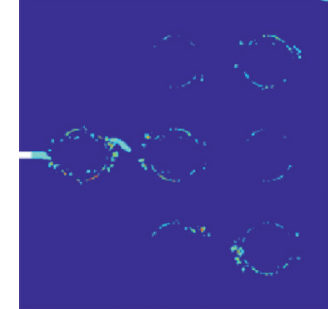

(b)

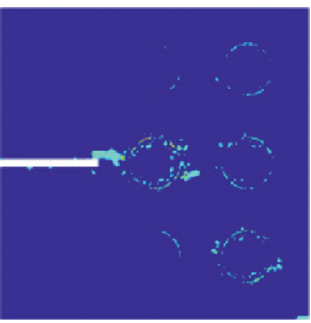

(g)

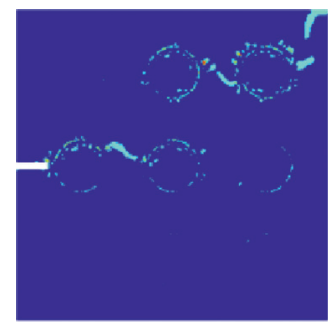

(c)

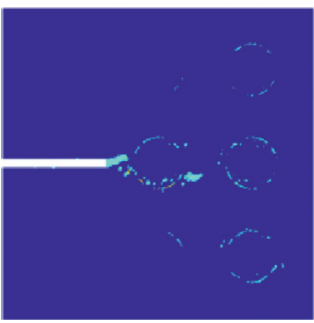

(h)

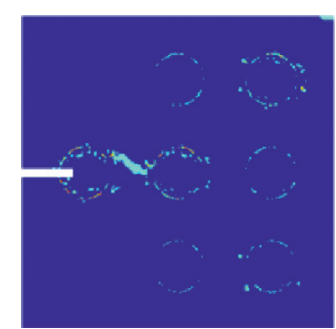

(d)

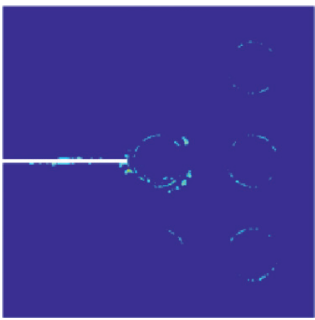

(i)

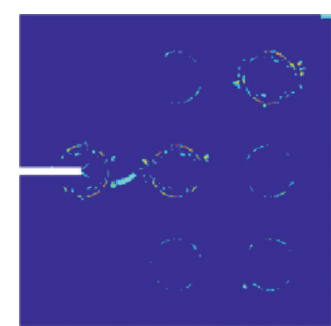

(e)

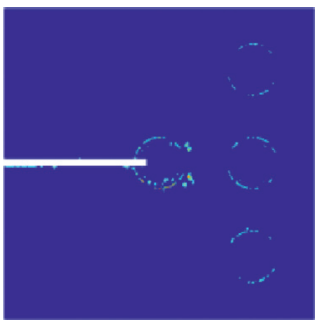

(j)

Figure 11: Crack path by increasing the pr-notch length: (a) length $=0 \mathrm{~mm}$; (b) length $=5 \mathrm{~mm}$; (c) length = $10 \mathrm{~mm}$; (d) length = $15 \mathrm{~mm}$; (e) length $=20 \mathrm{~mm}$; (f) length $=25 \mathrm{~mm}$; (g) length $=30 \mathrm{~mm}$; (h) length $=35 \mathrm{~mm}$; (i) length $=40 \mathrm{~mm}$; (j) length $=45 \mathrm{~mm}$.

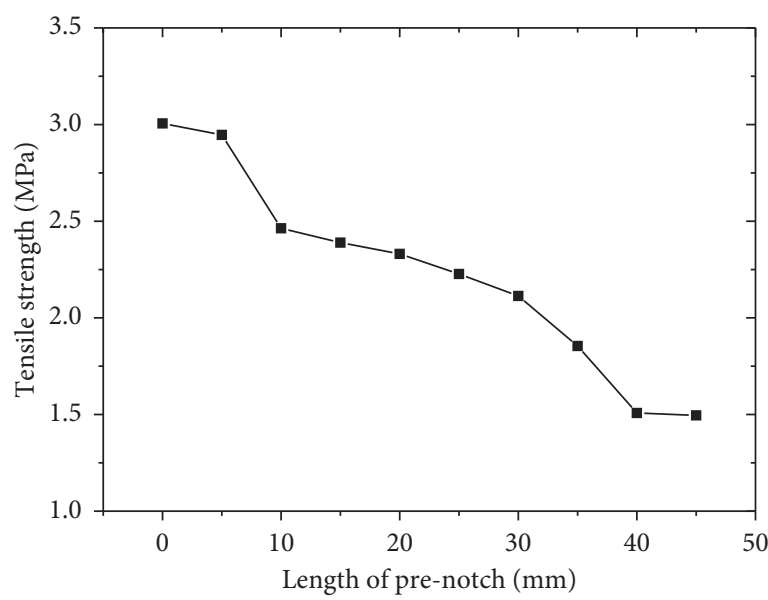

(a)

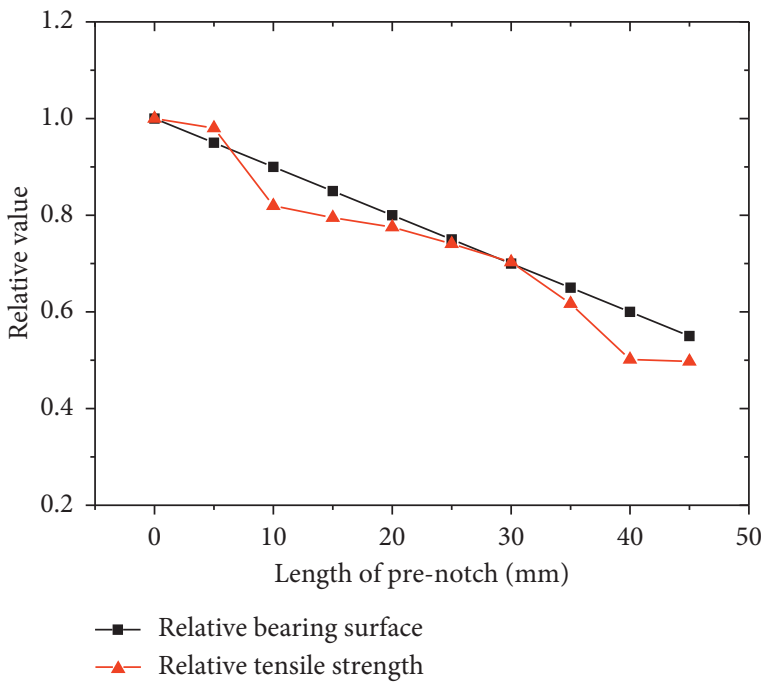

(b)

FIGURE 12: Effect of prenotch length: (a) tensile strength; (b) reduction trend.

4.1.2. Height of the Prenotch. Ten RAC models with different height sizes of prenotch varying from $5 \mathrm{~mm}$ to $50 \mathrm{~mm}$ were designed. Herein, the length size of these four models was $10 \mathrm{~mm}$. The effect of the prenotch height on the crack path and distribution is plotted in Figure 13.

As can be seen from Figure 13, there is only one continuous crack in the first six specimens of the prenotch height of 5 to $30 \mathrm{~mm}$, and this exhibition demonstrates that the effect of prenotch height on the crack path seems can be negligible. However, for the prenotch height between $35 \mathrm{~mm}$ to $50 \mathrm{~mm}$, more than one continuous crack has appeared in the specimen. The interpretation of these two different phenomena can be explained by the relative position between the prenotch to the recycled aggregate. As for the first case, only one recycled aggregate is adjacent to the prenotch and the mechanism of the prenotch height acting on the crack path seems to be similar. With the prenotch height increasing, another two recycled aggregates are adjacent to the prenotch, there is a stress concentration at the edge of the prenotch, and this stress concentration shares the loading of the recycled aggregate that is placed into the middle of the specimen. Further, owing to the stress concentration, more cracks are formed in the specimen, whereas the recycled aggregate that is adjacent to the middle of the prenotch only formed a few cracks; see Figure 13(j).

To further explain the effects of prenotch height on the tensile strength of RAC, the tensile strength of these 10 specimens are shown in Figure 14. Interestingly, as can be 


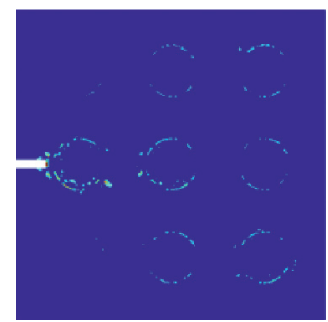

(a)

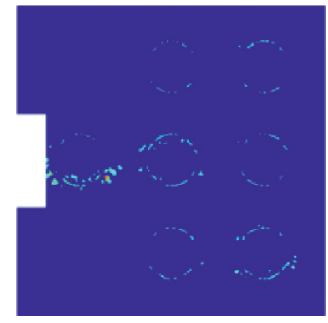

(f)

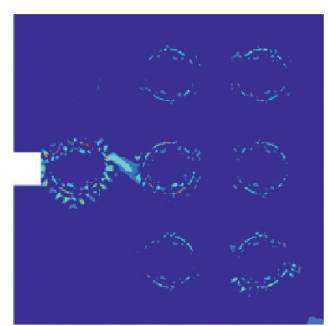

(b)

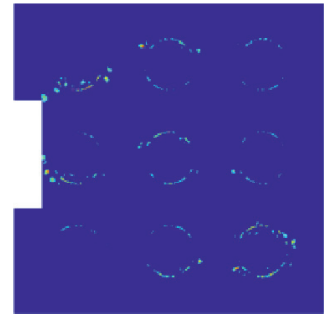

(g)

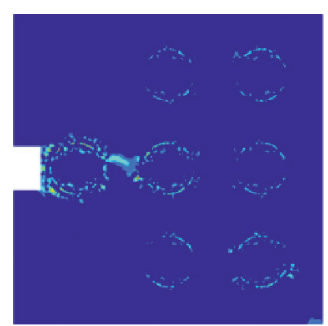

(c)

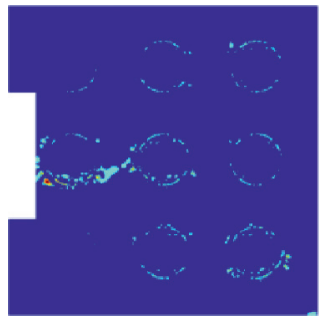

(h)

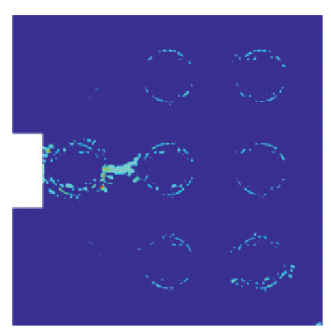

(d)

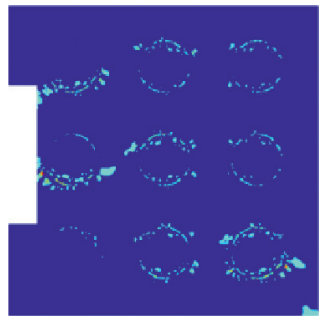

(i)

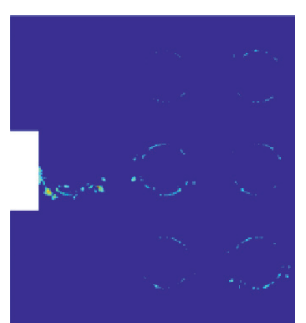

(e)

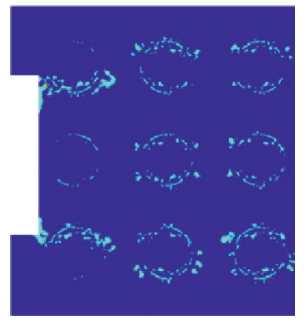

(j)

Figure 13: Crack path with different prenotch lengths: (a) length $=5 \mathrm{~mm}$; (b) length $=10 \mathrm{~mm}$; (c) length = $15 \mathrm{~mm}$; (d) length = $20 \mathrm{~mm}$; (e) length $=25 \mathrm{~mm}$; (f) length $=30 \mathrm{~mm}$; (g) length $=35 \mathrm{~mm}$; (h) length $=40 \mathrm{~mm}$; (i) length $=45 \mathrm{~mm}$; (j) height $=50 \mathrm{~mm}$.

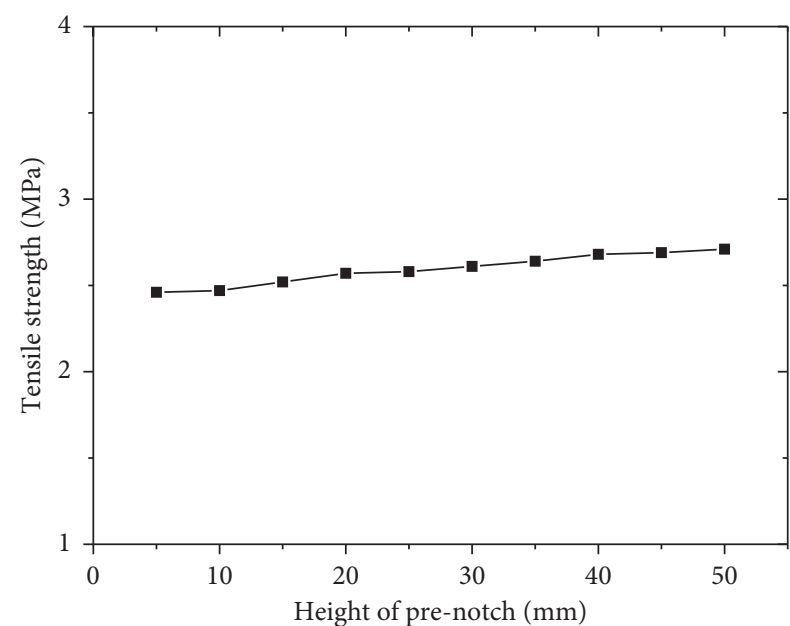

FIGURE 14: Effect of prenotch height on the tensile strength.

seen, an increase in the height of prenotch leads to a slight increase in the tensile strength. This fact may be explained by the decrease in the number of the cracks in the specimen, which absorbs more loading energy with the prenotch height increasing.

To summarize, both the length and the height of the prenotch have a meaningful effect on the crack path and distribution, whereas the length and the height show a different influence on tensile strength.

4.2. ITZ Thickness. The thickness of ITZ has been proved to have a significant effect on the mechanical properties of RAC and has been investigated in our previous work [15]. Previous work has shown that ITZ thickness has a meaningful effect on the compressive strength, elastic modulus, and peak strain and has a slight effect on the ultimate strain under uniaxial compression. In contrast, the thickness has a minor influence on those properties of RAC under uniaxial tension. In addition, the effect of the thickness of the old ITZ on the mechanical properties of the RAC is greater than that of the new ITZ. To avoid duplication of work, the effect of ITZ thickness on these parameters is not investigated in this article.

As for the cracking path, the thickness of ITZ has been proven to have an important effect on the crack path. The effect of ITZ thickness on the mechanical properties, i.e., tensile/compressive strength and peak/ultimate strain, was taken into consideration in most scientific works $[15,25,75,76]$; only a few works considered its effect on the crack path [15]. To further study its effect on the crack path, several numerical models of RAC by differing the ITZ thickness were established. In these models, only one recycled aggregate was manually placed into the specimen, which had a prenotch of $2 \mathrm{~mm} \times 10 \mathrm{~mm}$ and the ITZ size increasing from $0.05 \mathrm{~mm}$ to $1.5 \mathrm{~mm}$, as plotted in Figure 15 .

The simulated crack path of RAC models by increasing the ITZ thickness is plotted in Figure 16. As can be noticed, without regard to the ITZ thickness, the crack always formed at the ITZ zones; this phenomenon is in good agreement with others [34, 77-79]. Further, the cracks display a connection path that bypasses the recycled aggregate and penetrates the specimen. In the first case, for the models with an ITZ size of lesser $0.7 \mathrm{~mm}$, the crack width in the specimen is small and isolated, whereas, with an increased thickness of ITZ of more than $1.0 \mathrm{~mm}$, it can be clearly observed that the width of continuous crack increases significantly. Additionally, the width of cracks around the recycled aggregate has also increased.

4.3. Distance from Aggregate to Prenotch. Two types of specimen were designed by varying the distance (horizontal direction and vertical direction) from the prenotch to the edge of recycled aggregate to examine the force of the 


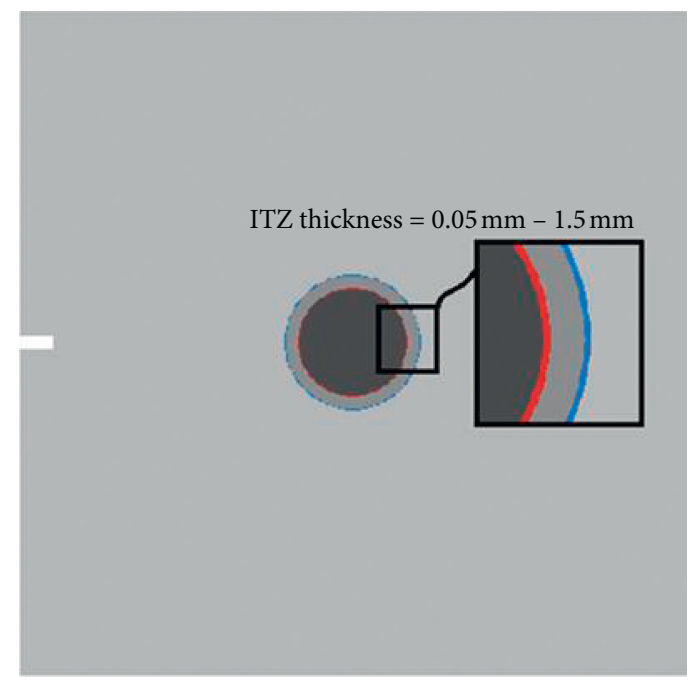

FIgURE 15: RAC model with different ITZ thicknesses.

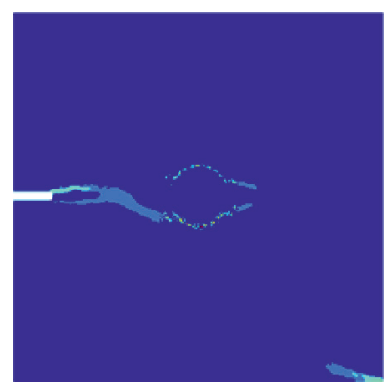

(a)

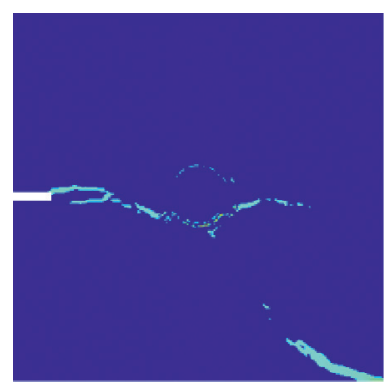

(e)

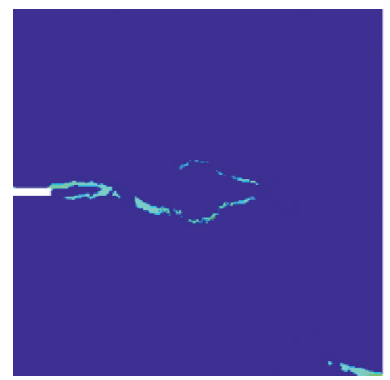

(i)

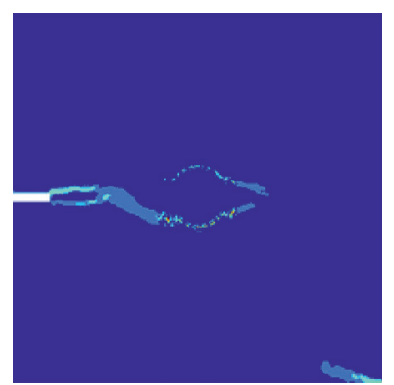

(b)

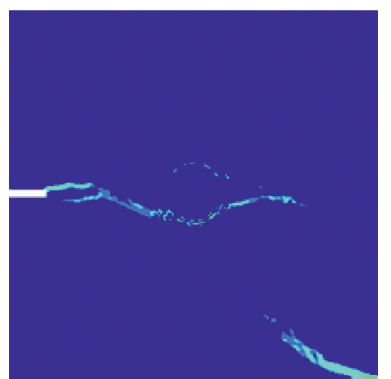

(f)

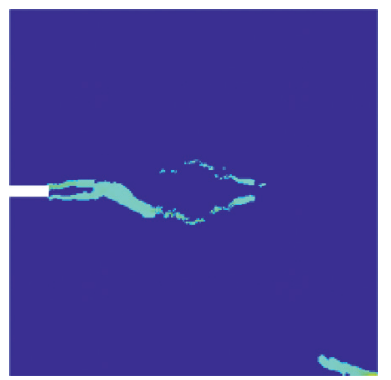

(j)

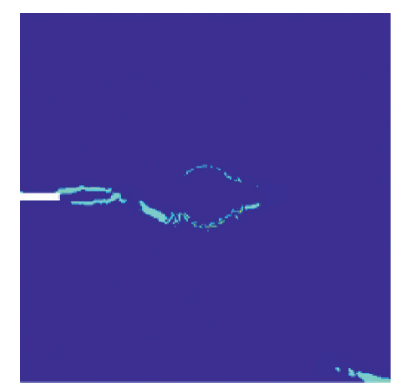

(c)

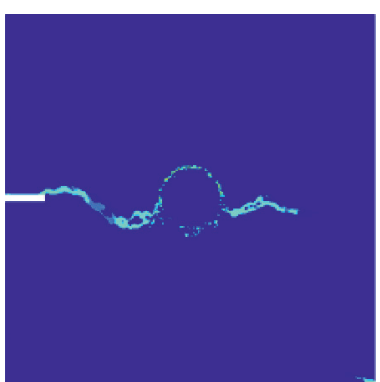

(g)

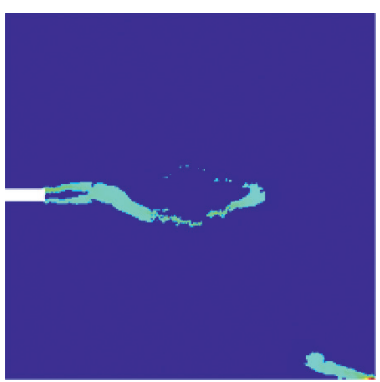

(k)

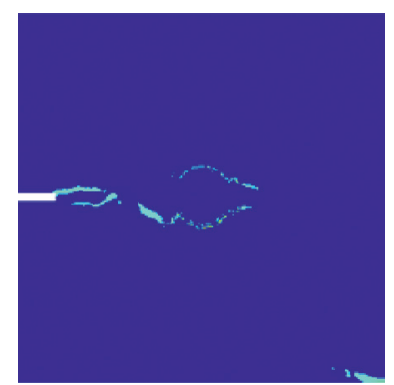

(d)

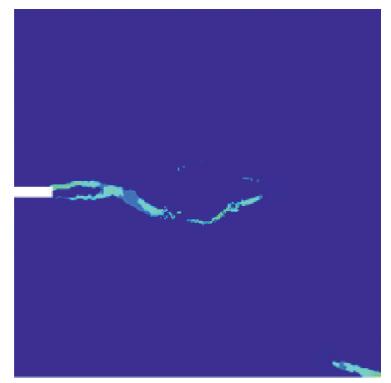

(h)

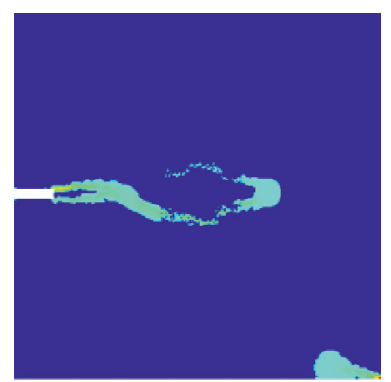

(l)

FIGURE 16: Crack path of RAC with different ITZ thicknesses. (a) ITZ $=0.05 \mathrm{~mm}$. (b) ITZ=0.06 mm. (c) ITZ=0.07 mm. (d) ITZ=0.08 $\mathrm{mm}$. (e) $I T Z=0.09 \mathrm{~mm}$. (f) $I T Z=0.1 \mathrm{~mm}$. (g) ITZ $=0.3 \mathrm{~mm}$. (h) $I T Z=0.5 \mathrm{~mm}$. (i) $I T Z=0.7 \mathrm{~mm}$. (j) $I T Z=1.0 \mathrm{~mm}$. (k) ITZ=1.2 $\mathrm{mm}$. (l) $\mathrm{ITZ}=1.5 \mathrm{~mm}$ 
recycled aggregate location on the crack pattern of the prenotched specimen. Additionally, several numerical models for prenotching recycled aggregate were designed and simulated. These models include only one aggregate to avoid other influences (e.g., aggregate distribution and size, length, and height of the prenotch). It is worth mentioning that, for these models, each prenotch is of the size of $2 \mathrm{~mm} \times 5 \mathrm{~mm}$.

4.3.1. Horizontal Distance. The numerical models of the RAC by varying the horizontal direction of recycled aggregate are displayed in Figure 17. Herein, the distance increases stepwise from $-5 \mathrm{~mm}$ to $35 \mathrm{~mm}$ with a step of $5 \mathrm{~mm}$. Note that for the $-5 \mathrm{~mm}$ step, this model corresponds to the specimen in which the aggregate was notched in the structure.

The obtained simulated crack paths by increasing distance $r_{x}$ are exhibited in Figure 18. It can be clearly observed that the recycled aggregate location is of major significance to the crack path. What is interesting in Figure 18 is that for the model of the notched aggregate, the aggregate was broken and formed two long continuous cracks in the specimen on both sides. Additionally, this failure mode shows a significant difference compared to others. As distance $r_{x}$ is less than $10 \mathrm{~mm}$, namely, 1.0 times of radius of the recycled aggregate, two continuous cracks are formed in the cap and bottom zones of the recycled aggregate. Further, there is only one continuous crack running through the specimen, which is in good agreement with other results $[15,39,80]$. When distance $r_{x}$ is increasedfrom $15 \mathrm{~mm}$ to $25 \mathrm{~mm}$, which is $1.5-2.5$ times the radius of the recycled aggregate, only one continuous crack is formed in the specimen, instead of two continuous cracks around the recycled aggregate. By further increasing distance $r_{x}$ to $30 \mathrm{~mm}$ or $35 \mathrm{~mm}$, that is 3.0 or 3.5 times the radius of recycled aggregate, the location of aggregate seems to have an ignorable effect on the crack path. These phenomena can be explained by the fact the zones near the prenotched position have a stress concentration; therefore, the first crack is formed in these zones. As for the recycled aggregate, the five-phase system has five different elastic moduli: the elastic moduli of transfer zones between different phases have a sudden alteration, and thereby these transfer zones also have a stress concentration; these two stress concentration zones affect each other within a certain distance $r_{x}$.

4.3.2. Vertical Distance. The numerical models of the RAC with different vertical directions of recycled aggregate are presented in Figure 19. Herein, the distance fx3 rises stepwise from $0 \mathrm{~mm}$ to $35 \mathrm{~mm}$, in which the step is $5 \mathrm{~mm}$. Further, a comparative model that does not contain recycled aggregate was also established to analyze the crack paths.

The crack paths with different distances $r_{y}$ are exhibited in Figure 20. As for the model without recycled aggregate, which means this model is a cement mortar model, the crack path of this model provides a reference sample for the RAC models.

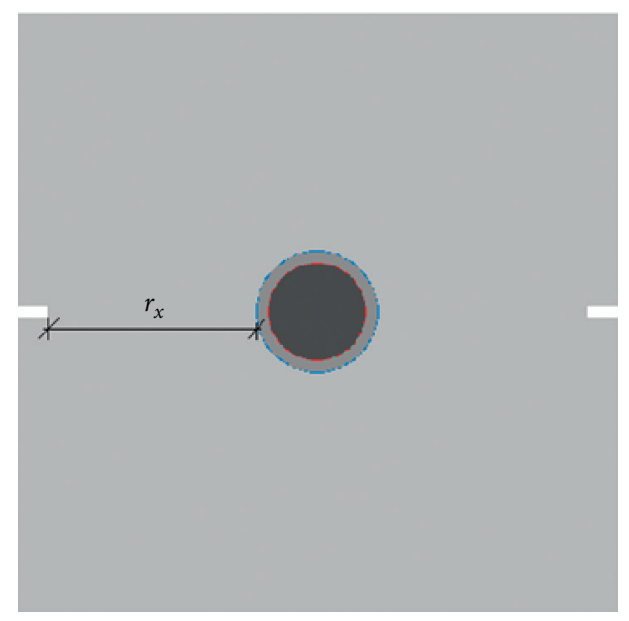

Figure 17: RAC model with one aggregate.

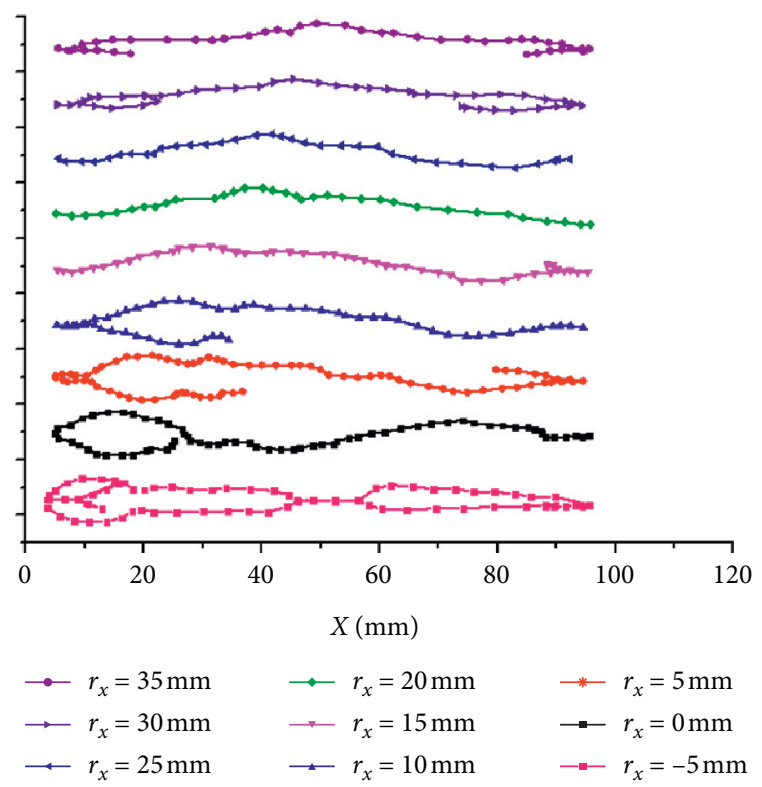

Figure 18: Crack path with different distances $r_{x}$.

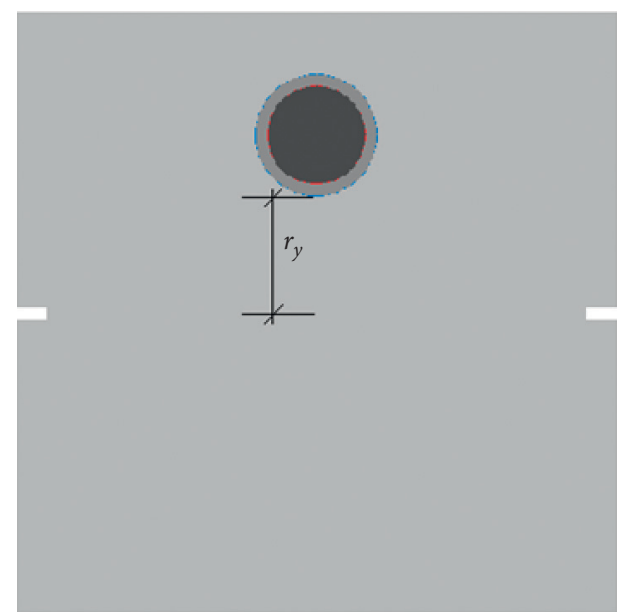

Figure 19: RAC model with one aggregate. 


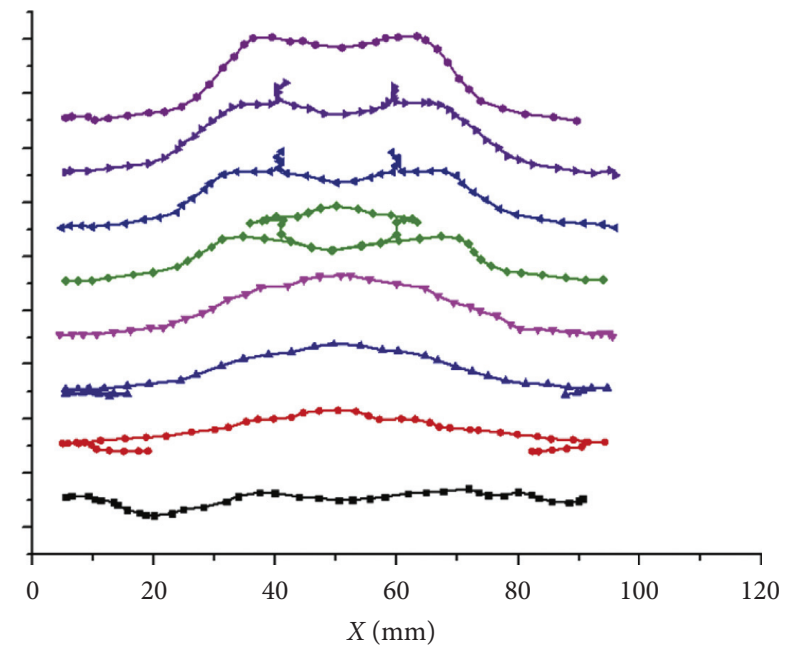

$$
\begin{array}{ll}
\multimap r_{y}=35 \mathrm{~mm} & \rightarrow r_{y}=15 \mathrm{~mm} \\
\rightarrow r_{y}=30 \mathrm{~mm} & \longrightarrow r_{y}=10 \mathrm{~mm} \\
\multimap r_{y}=25 \mathrm{~mm} & \rightarrow r_{y}=5 \mathrm{~mm} \\
\multimap r_{y}=20 \mathrm{~mm} & \rightarrow \text { No aggregate }
\end{array}
$$

FIGURE 20: Crack path with different distances $r_{y}$.

When distance $r_{y}$ is increased to $15 \mathrm{~mm}$, that is 3.0 times the radius of recycled aggregate, only an individual continuous crack appears in the specimen. There is a significant difference between the models of distance $r_{y}$ increasing from $20 \mathrm{~mm}$ to $35 \mathrm{~mm}$; in addition to continuous crack, several short isolated cracks have also emerged around the recycled aggregate. Interestingly, for those subjects of $r_{y}$ between $20 \mathrm{~mm}$ to $35 \mathrm{~mm}$, the short isolated cracks exhibit a decreasing trend. These facts indicate that the vertical distance of the recycled aggregate between the prenotch also has a meaningful effect on the crack path, and the influence distance can be expanded to at least 3.5 times the radius of aggregate. The mechanism of this case could be explained by the fact of the stress concentration around the recycled aggregate due to the difference of the elastic modulus in the five-phase system.

To sum up, these simulation results displayed above demonstrated that distance $r_{y}$ has a significant effect on both the crack path compared to that of distance $r_{x}$.

\section{Conclusion}

In the current article, a mesh mode of RAC in which the thickness of ITZ can be characteristic of an actual thickness was presented. A new FEM based on the complementary energy principle was applied to describe the mechanical behavior of the RAC system under uniaxial tensile load. The effects of prenotch length and height on the crack path were studied. Further, the influences of ITZ thickness and the distance from the aggregate to the prenotch on the crack path were also conducted. Several points can be summarized as follows.

(1) The mesh mode of RAC can be applied to the characteristic mesostructure of RAC that can describe the ITZ thickness as an actual thickness. The
FEM on the complementary energy principle is also an efficient mathematical method, which can express the compliance matrix of the element with any shape to be an explicit expression.

(2) The length of the prenotch acts as a significant effect on the crack path and tensile strength. With increasing the prenotch length, the number of isolated cracks shows a gradually decreasing trend. As for the tensile strength, the decreasing trend displays a correlation with the relative bearing surface.

(3) The height of the prenotch also has a meaningful influence on the crack path and has an effect of weakly enhancing the tensile strength. With the prenotch height increasing, the number of isolated cracks increases significantly. Particularly, this phenomenon is more pronounced at the ends of the prenotch. As for the tensile strength, there is a slight increase with the increase of prenotch height.

(4) The thickness of ITZ has an important effect on the width and length of the crack path. With the ITZ size increasing, the width of the continuous crack increases. Further, the isolated crack around the recycled aggregate developed, except for the old ITZ, and both the new ITZ and adhered mortar also failed.

(5) As for the effect of the horizontal distance between the prenotch to the recycled aggregate on the crack path, with increasing the horizontal distance, the degree of the influence gradually decreases. In particular, the number of continuous cracks has also been reduced from two to one.

(6) The effect of the vertical distance between the prenotch to the recycled aggregate on the crack path shows a significant difference compared to the horizontal distance. An increasing vertical distance results in an increase in effect degree of the crack pattern; both the shape and the path of the continuous cracks will change dramatically.

This model still has some shortcomings. For instance, the RAC model is two-dimensional and the corresponding three-dimensional model has not been developed. In addition, the randomness of the attached mortar distribution and the void content has not been considered. Also, it is assumed that the aggregates are ordinary inert aggregates with a circular shape, which is the idealized numerical model of RAC. Besides, only the static load problem has been investigated; dynamic load and active powder have not been considered. The multiaxial loading model has not been established. Future work is warranted to improve the model, taking into consideration the above factors and more complex microstructural features. These issues will be studied and considered in our future work.

\section{Data Availability}

The data used to support the findings of this study are currently under embargo while the research findings are 
commercialized. Requests for data after publication of this article will be considered by the corresponding author.

\section{Conflicts of Interest}

The authors declare that they have no conflicts of interest.

\section{Acknowledgments}

The authors would like to acknowledge the Natural Science Foundation of the Jiangsu Higher Education Institutions of China (nos. 19KJB560006 and 20KJB560033), a project supported by the scientific research fund of Yancheng Polytechnic College (nos. ygy1902 and ygy202007), and the Technology Innovation Team of Jiangsu Province (Jiangsu Teacher, 2017 No.51).

\section{References}

[1] D. Mindess, S. Francis, and Y. J. Darwin, Concrete, PrenticeHall, Upper Saddle River, Bergen, Norway, 2nd edition, 2003.

[2] G. L. Golewski, "Measurement of fracture mechanics parameters of concrete containing fly ash thanks to use of digital image correlation (DIC) method," Measurement, vol. 135, pp. 96-105, 2019.

[3] P. Chen, C. Liu, and Y. Wang, "Size effect on peak axial strain and stress-strain behavior of concrete subjected to axial compression," Construction and Building Materials, vol. 188, pp. 645-655, 2018.

[4] G. L. Golewski, "A novel specific requirements for materials used in reinforced concrete composites subjected to dynamic loads," Composite Structures, vol. 223, Article ID 110939, 2019.

[5] G. L. Golewski, "New principles for implementation and operation of foundations for machines: a review of recent advances," Structural Engineering and Mechanics, vol. 71, no. 3, pp. 317-327, 2019.

[6] D.-K. Thai, T. M. Tu, T. Q. Bui, and T. T. Bui, "Gradient tree boosting machine learning on predicting the failure modes of the RC panels under impact loads," Engineering with Computers, vol. 37, pp. 597-608, 2021.

[7] V. W. Y. Tam, M. Soomro, and A. C. J. Evangelista, "A review of recycled aggregate in concrete applications (2000-2017)," Construction and Building Materials, vol. 172, pp. 272-292, 2018.

[8] P. Zhu, M. Hua, H. Liu, X. Wang, and C. Chen, "Interfacial evaluation of geopolymer mortar prepared with recycled geopolymer fine aggregates," Construction and Building Materials, vol. 259, Article ID 119849, 2020.

[9] A. Mistri, S. K. Bhattacharyya, N. Dhami, A. Mukherjee, and S. V. Barai, "A review on different treatment methods for enhancing the properties of recycled aggregates for sustainable construction materials," Construction and Building Materials, vol. 233, Article ID 117894, 2020.

[10] R. Wang, N. Yu, and Y. Li, "Methods for improving the microstructure of recycled concrete aggregate: a review," Construction and Building Materials, vol. 242, Article ID 121490, 2020.

[11] C. Thomas, J. de Brito, A. Cimentada, and J. A. Sainz-Aja, "Macro- and micro- properties of multi-recycled aggregate concrete," Journal of Cleaner Production, vol. 245, Article ID 118843, 2020.
[12] K. McNeil and T. H.-K. Kang, "Recycled concrete aggregates: a review," International Journal of Concrete Structures and Materials, vol. 7, no. 1, pp. 61-69, 2013.

[13] R. Muduli and B. B. Mukharjee, "Performance assessment of concrete incorporating recycled coarse aggregates and metakaolin: a systematic approach," Construction and Building Materials, vol. 233, Article ID 117223, 2020.

[14] Z. Zhang, K. Wang, H. Liu, and Z. Deng, "Key performance properties of asphalt mixtures with recycled concrete aggregate from low strength concrete," Construction and Building Materials, vol. 126, pp. 711-719, 2016.

[15] Y. Wang, Y. Peng, M. M. A. Kamel, and L. Gong, "Modeling interfacial transition zone of RAC based on a degenerate element of BFEM," Construction and Building Materials, vol. 252, Article ID 119063, 2020.

[16] Y. Wang, Y. Peng, M. M. A. Kamel, and L. Ying, "Mesomechanical properties of concrete with different shapes and replacement ratios of recycled aggregate based on base force element method," Structural Concrete, vol. 20, no. 4, pp. 1425-1437, 2019.

[17] C. Thomas, J. Setién, J. A. Polanco, J. de Brito, and F. Fiol, "Micro- and macro-porosity of dry- and saturated-state recycled aggregate concrete," Journal of Cleaner Production, vol. 211, pp. 932-940, 2019.

[18] C. Liu, H. Liu, J. Xiao, and G. Bai, "Effect of old mortar pore structure on relative humidity response of recycled aggregate concrete," Construction and Building Materials, vol. 247, Article ID 118600, 2020.

[19] P. Zhu, Y. Hao, H. Liu, D. Wei, S. Liu, and L. Gu, “Durability evaluation of three generations of $100 \%$ repeatedly recycled coarse aggregate concrete," Construction and Building Materials, vol. 210, pp. 442-450, 2019.

[20] W. Li, C. Long, V. W. Y. Tam, C.-S. Poon, and W. Hui Duan, "Effects of nano-particles on failure process and microstructural properties of recycled aggregate concrete," Construction and Building Materials, vol. 142, pp. 42-50, 2017.

[21] T. Meng, J. Zhang, H. Wei, and J. Shen, "Effect of nanostrengthening on the properties and microstructure of recycled concrete," Nanotechnology Reviews, vol. 9, no. 1, pp. 79-92, 2020.

[22] G. L. Golewski, "Energy savings associated with the use of fly ash and nanoadditives in the cement composition," Energies, vol. 13, p. 9, 2020.

[23] J. Xiao, W. Li, D. J. Corr, and S. P. Shah, "Effects of interfacial transition zones on the stress-strain behavior of modeled recycled aggregate concrete," Cement and Concrete Research, vol. 52, pp. 82-99, 2013.

[24] G. L. Golewski, "The influence of microcrack width on the mechanical parameters in concrete with the addition of fly ash: consideration of technological and ecological benefits," Construction and Building Materials, vol. 197, pp. 849-861, 2018.

[25] S.-M. Kim and R. K. Abu Al-Rub, "Meso-scale computational modeling of the plastic-damage response of cementitious composites," Cement and Concrete Research, vol. 41, no. 3, pp. $339-358,2011$.

[26] A. SkarÅyÅski, M. Nitka, and J. Tejchman, "Modelling of concrete fracture at aggregate level using FEM and DEM based on X-ray $\hat{I}^{1} 1 / 4 \mathrm{CT}$ images of internal structure," Engineering Fracture Mechanics, vol. 147, pp. 13-35, 2015.

[27] L. Jin, W. Yu, X. Du, and W. Yang, "Mesoscopic numerical simulation of dynamic size effect on the splitting-tensile strength of concrete," Engineering Fracture Mechanics, vol. 209, pp. 317-332, 2019. 
[28] M. Guo, F. Grondin, and A. Loukili, "Numerical method to model the creep of recycled aggregate concrete by considering the old attached mortar," Cement and Concrete Research, vol. 118, pp. 14-24, 2019.

[29] X. Du, L. Jin, and G. Ma, "Meso-element equivalent method for the simulation of macro mechanical properties of concrete," International Journal of Damage Mechanics, vol. 22, no. 5, pp. 617-642, 2012.

[30] Q. Xiong, X. Wang, and A. P. Jivkov, “A 3D multi-phase meso-scale model for modelling coupling of damage and transport properties in concrete," Cement and Concrete Composites, vol. 109, 2020.

[31] X. Wang and A. P. Jivkov, "Combined numerical-statistical analyses of damage and failure of $2 \mathrm{D}$ and 3D mesoscale heterogeneous concrete," Mathematical Problems in Engineering, vol. 2015, Article ID 702563, 12 pages, 2015.

[32] T.-T. Nguyen, D. Waldmann, and T. Q. Bui, "Computational chemo-thermo-mechanical coupling phase-field model for complex fracture induced by early-age shrinkage and hydration heat in cement-based materials," Computer Methods in Applied Mechanics and Engineering, vol. 34828 pages, 2019.

[33] Z. M. Wang, A. K. H. Kwan, and H. C. Chan, "Mesoscopic study of concrete I: generation of random aggregate structure and finite element mesh," Computers \& Structures, vol. 70, no. 5, pp. 533-544, 1999.

[34] D. Asahina, E. N. Landis, and J. E. Bolander, "Modeling of phase interfaces during pre-critical crack growth in concrete," Cement and Concrete Composites, vol. 33, no. 9, pp. 966-977, 2011.

[35] J. J. E. Bolander and S. Saito, "Fracture analyses using spring networks with random geometry," Engineering Fracture Mechanics, vol. 61, no. 5-6, pp. 569-591, 1998.

[36] K. Nagai, Y. Sato, and T. Ueda, "Mesoscopic simulation of failure of mortar and concrete by 2D RBSM," Journal of Advanced Concrete Technology, vol. 2, no. 3, pp. 359-374, 2004.

[37] T. Rabczuk, G. Zi, S. Bordas, and H. Nguyen-Xuan, "A geometrically non-linear three-dimensional cohesive crack method for reinforced concrete structures," Engineering Fracture Mechanics, vol. 75, no. 16, pp. 4740-4758, 2008.

[38] L. Jin, Z. Ding, D. Li, and X. Du, "Experimental and numerical investigations on the size effect of moderate high-strength reinforced concrete columns under small-eccentric compression," International Journal of Damage Mechanics, vol. 27, no. 5, pp. 657-685, 2017.

[39] W. Li, Z. Luo, Z. Sun, Y. Hu, and W. H. Duan, "Numerical modelling of plastic-damage response and crack propagation in RAC under uniaxial loading," Magazine of Concrete Research, vol. 70, no. 9, pp. 459-472, 2018.

[40] M. Guo, F. Grondin, and A. Loukili, "Numerical analysis of the failure of recycled aggregate concrete by considering the random composition of old attached mortar," Journal of Building Engineering, vol. 28, Article ID 101040, 2020.

[41] P. S. M. Thilakarathna, K. S. Kristombu Baduge, P. Mendis, V. Vimonsatit, and H. Lee, "Mesoscale modelling of concrete â€ a review of geometry generation, placing algorithms, constitutive relations and applications," Engineering Fracture Mechanics, vol. 231, 2020.

[42] X. Ruan, Y. Li, Z. Jin, Z. Pan, and Z. Yin, "Modeling method of concrete material at mesoscale with refined aggregate shapes based on image recognition," Construction and Building Materials, vol. 204, pp. 562-575, 2019.

[43] H. Gao, X. Yang, and C. Zhang, "Experimental and numerical analysis of three-point bending fracture of pre-notched asphalt mixture beam," Construction and Building Materials, vol. 9010 pages, 2015.

[44] M. A. Msekh, N. H. Cuong, G. Zi, P. Areias, X. Zhuang, and T. Rabczuk, "Fracture properties prediction of clay/epoxy nanocomposites with interphase zones using a phase field model," Engineering Fracture Mechanics, vol. 188, pp. 287299, 2018.

[45] K. M. Hamdia, M. Silani, X. Zhuang, P. He, and T. Rabczuk, "Stochastic analysis of the fracture toughness of polymeric nanoparticle composites using polynomial chaos expansions," International Journal of Fracture, vol. 206, no. 2, pp. 215-227, 2017.

[46] A. Chen, X. Xia, Q. Zhang, and M. Wu, "The meso-level numerical experiment research of the mechanics properties of recycled concrete," Journal of Software, vol. 7, p. 9, 2012.

[47] S. S. Chen, Q. H. Li, Y. H. Liu, and Z. Q. Xue, "A meshless local natural neighbour interpolation method for analysis of twodimensional piezoelectric structures," Engineering Analysis with Boundary Elements, vol. 37, no. 2, pp. 273-279, 2013.

[48] T. Rabczuk, G. Zi, S. Bordas, and H. Nguyen-Xuan, "A simple and robust three-dimensional cracking-particle method without enrichment," Computer Methods in Applied Mechanics and Engineering, vol. 199, pp. 37-40, 2010.

[49] X. Tan, W. Li, M. Zhao, and V. W. Y. Tam, "Numerical discrete-element method investigation on failure process of recycled aggregate concrete," Journal of Materials in Civil Engineering, vol. 31, p. 1, Article ID 04018353, 2018.

[50] M. Nitka and J. Tejchman, "Meso-mechanical modelling of damage in concrete using discrete element method with porous ITZs of defined width around aggregates," Engineering Fracture Mechanics, vol. 231, Article ID 107029, 2020.

[51] F. Mohebbi, B. Evans, and T. Rabczuk, "Solving direct and inverse heat conduction problems in functionally graded materials using an accurate and robust numerical method," International Journal of Thermal Sciences, vol. 159, Article ID 106629, 2021.

[52] C. Zhang, S. S. Nanthakumar, T. Lahmer, and T. Rabczuk, "Multiple cracks identification for piezoelectric structures," International Journal of Fracture, vol. 206, no. 2, pp. 151-169, 2017.

[53] L. Shi, T. Yu, and T. Q. Bui, "Numerical modelling of hydraulic fracturing in rock mass by xfem," Soil Mechanics and Foundation Engineering, vol. 52, no. 2, pp. 74-83, 2015.

[54] W. Fang, J. Wu, T. Yu, T.-T. Nguyen, and T. Q. Bui, "Simulation of cohesive crack growth by a variable-node XFEM," Frontiers of Structural and Civil Engineering, vol. 14, no. 1, pp. 215-228, 2019.

[55] T. H. H. Pian and K. Sumihara, "Rational approach for assumed stress finite elements," International Journal for $\mathrm{Nu}$ merical Methods in Engineering, vol. 20, no. 9, pp. 1685-1695, 2010.

[56] C. Zhang, D. Wang, J. Zhang, W. Feng, and Q. Huang, "On the equivalence of various hybrid finite elements and a new orthogonalization method for explicit element stiffness formulation," Finite Elements in Analysis and Design, vol. 43, no. 4, pp. 321-332, 2007.

[57] R. L. Taylor, P. J. Beresford, and E. L. Wilson, "A non-conforming element for stress analysis," International Journal for Numerical Methods in Engineering, vol. 10, no. 6, pp. 1211-1219, 1976.

[58] E. T. Ooi, S. Rajendran, and J. H. Yeo, “A 20-node hexahedron element with enhanced distortion tolerance," International Journal for Numerical Methods in Engineering, vol. 60, no. 15, pp. 2501-2530, 2004. 
[59] T.-T. Nguyen, D. Waldmann, and T. Q. Bui, "Phase field simulation of early-age fracture in cement-based materials," International Journal of Solids and Structures, vol. 191-192, pp. 157-172, 2020.

[60] W. Chen, Plasticity in Reinforced Concrete, J Ross Publishing, Plantation, FL, USA, 2007.

[61] D. J. Han and W. F. Chen, "A nonuniform hardening plasticity model for concrete materials," Mechanics of Materials, vol. 4, no. 3-4, pp. 283-302, 1985.

[62] P. J. Yoder and W. D. Iwan, "On the formulation of strainspace plasticity with multiple loading surfaces," Journal of Applied Mechanics, vol. 48, no. 4, pp. 773-778, 1981.

[63] Z. Bazant, "Plastic fracturing theory for concrete," Journal of Engineering Mechanics-ASCE, vol. 105, pp. 407-428, 1979.

[64] H. Balke, N. Cristescu, and L. V.. Suliciu, "The hague-bostonlondon, martinus nijhoff publ. by 1982. ISBN 90â€ 247â€ 2592â€ 5 (mechanics of plastic solids 5). ZAMM â€," Journal of Applied Mathematics and Mechanics/Zeitschrift fÃr Angewandte Mathematik und Mechanik, vol. 64, no. 8, p. 375, 1984.

[65] Z. P. Bazant and P. D. Bhat, "Endochronic theory of inelasticity and failure of concrete," Journal of Engineering Mechanics-ASCE, vol. 102, 1976.

[66] S. Yazdani and H. L. Schreyer, "Combined plasticity and damage mechanics model for plain concrete," Journal of Engineering Mechanics, vol. 116, no. 7, pp. 1435-1450, 1990.

[67] N. Ottosen, "Constitutive model for shortâ€time loading of concrete," Journal of Engineering Mechanics Division, vol. 105, p. 1, 1979.

[68] Z. Guo, Y. Guo, and X. Yan, "A non â€ linear elastic orthotropic constitutive model of concrete," Journal of Tsinghua University, vol. 37, no. 6, pp. 78-81, 1997.

[69] Y. Wang, Y. Peng, M. M. A. Kamel, and L. Ying, "Base force element method based on the complementary energy principle for the damage analysis of recycled aggregate concrete," International Journal for Numerical Methods in Engineering, vol. 121, no. 7, pp. 1484-1506, 2020.

[70] W. Li, J. Xiao, Z. Sun, and S. P. Shah, "Failure processes of modeled recycled aggregate concrete under uniaxial compression," Cement and Concrete Composites, vol. 34, no. 10, pp. 1149-1158, 2012.

[71] Y. Peng and Y. Liu, "Base force element method of complementary energy principle for large rotation problems," Acta Mechanica Sinica, vol. 25, no. 4, pp. 507-515, 2009.

[72] M. P. Lutz, P. J. M. Monteiro, and R. W. Zimmerman, "Inhomogeneous interfacial transition zone model for the bulk modulus of mortar," Cement and Concrete Research, vol. 27, no. 7, pp. 1113-1122, 1997.

[73] P. Mondal, S. P. Shah, and L. D. Marks, "Nanomechanical properties of interfacial transition zone in concrete," in Nanotechnology in Construction 3, Z. Bittnar, J. NeËmecËek, V. Åmilauer, and J. Zeman, Eds., pp. 315-320, Springer, Berlin, Heidelberg, Germany, 2009.

[74] L. Ying, Y. Peng, and H. Yang, "Meso-analysis of dynamic compressive behavior of recycled aggregate concrete using BFEM," International Journal of Computational Methods, vol. 17, no. 06, Article ID 1950013, 2019.

[75] L. Jin, T. Wang, X.-a. Jiang, and X. Du, "Size effect in shear failure of RC beams with stirrups: simulation and formulation," Engineering Structures, vol. 199, Article ID 109573, 2019.

[76] Z. Song and Y. Lu, "Mesoscopic analysis of concrete under excessively high strain rate compression and implications on interpretation of test data," International Journal of Impact Engineering, vol. 46, pp. 41-55, 2012.
[77] Y. J. Peng, L. Ying, M. M. A. Kamel, and Y. Wang, "Mesoscale fracture analysis of recycled aggregate concrete based on digital image processing technique," Structural Concrete, vol. 115 pages, 2020.

[78] W. Zhang, S. Wang, P. Zhao, L. Lu, and X. Cheng, "Effect of the optimized triple mixing method on the ITZ microstructure and performance of recycled aggregate concrete," Construction and Building Materials, vol. 203, pp. 601-607, 2019.

[79] T. Li, J. Xiao, Y. Zhang, and B. Chen, "Fracture behavior of recycled aggregate concrete under three-point bending," Cement and Concrete Composites, vol. 104, 2019.

[80] G. Lilliu and J. G. M. van Mier, "On the relative use of micromechanical lattice analysis of 3-phase particle composites," Engineering Fracture Mechanics, vol. 74, no. 7, pp. 1174-1189, 2007. 